\title{
DYNAMIC COMPRESSION AND VOLATILE RELEASE OF CARBONATES
}

\author{
James A. Tyburczy and Thomas J. Ahrens
}

Seismological Laboratory, California Institute of Technology, Pasadena

\begin{abstract}
Particle velocity profiles upon shock compression and adiabatic release were measured for polycrystalline calcite (Solenholen limestone) to $12-24 \mathrm{GPa}$ and for porous calcite (Dover chalk, $\rho_{\mathrm{o}}=1.40 \mathrm{~g} / \mathrm{cm}^{3}, 49 \%$ porosity) to between 5 and $11 \mathrm{GPa}$. The electromagnetic particle velocity gauge method was used. Upon shock compression of Solenhofen limestone, the Hugoniot elastic limit was determined to vary from 0.36 to $0.45 \mathrm{GPa}$. Transition shocks at between 2.5 and $3.7 \mathrm{GPa}$, possibly arising from the calcite II-III transition, were observed. For the Solenhofen limestone, the release paths lie relatively close to the Hugoniot. Evidence for the occurrence of the calcite III-II transition upon release was observed, but no rarefaction shocks were detected. Initial release wave speeds suggest retention of shear strength up to at least $20 \mathrm{GPa}$, with a possible loss of shear strength at higher pressures. The measured equation of state is used to predict the fraction of material devolatilized upon adiabatic release as a function of shock pressure. The effect of ambient partial pressure of $\mathrm{CO}_{2}$ on the calculations is demonstrated. $\mathrm{P}_{\mathrm{CO}_{2}}$ should be taken into account in models of atmospheric evolution by means of impact-induced mineral devolatilization. Mass fractions of $\mathrm{CO}_{2}$ released expected on the basis of a continuum model are much lower than determined experimentally. This discrepancy, and radiative characteristics of shocked calcite, indicate that localization of thermal energy (shear banding) occurs under shock compression even though no solid-solid transitions occur in this pressure range. Release adiabatic data indicate that Dover chalk loses its shear strength when shocked to $10 \mathrm{GPa}$ pressure. At $5 \mathrm{GPa}$ the present data are ambiguous regarding shear strength. For Dover chalk, continuum shock entropy calculations result in a minimum estimate of $90 \%$ devolatilization upon complete release from $10 \mathrm{GPa}$. For calcite, isentropic release paths from calculated continuum Hugoniot temperatures cross in to the $\mathrm{CaO}$ (solid) $+\mathrm{CO}_{2}$ (vapor) field at improbably low pressures (for example, $1^{-7} \mathrm{GPa}$ for a shock pressure of $25 \mathrm{GPa}$ ). However, calculated isentropic release paths originating from $\mathrm{PT}$ points corresponding to previous color temperature under shock measurements cross in to the melt plus vapor field at pressures greater than $0.5 \mathrm{GPa}$, suggesting that devolatilization is initiated at the shear banding sites.
\end{abstract}

\section{Introduction}

The shock compression and release behavior of carbonates is of interest in the study of cratering mechanics, shock metamorphism in carbonate terranes, and the generation of $\mathrm{CO}_{2}$-bearing atmospheres on the terrestrial planets. Approximately $30 \%$ of the known or probable terrestrial meteorite impact craters occur at least partially in carbonate rocks [Grieve and Robertson, 1979]. Impactinduced devolatilization of hydrous and carbonate minerals appears to play a role in the evolution of terrestrial planetary atmospheres [Lange and Ahrens, 1983, and unpublished manuscript, 1985].

Calcite phase transitions under static and dynamic

\section{Copyright 1986 by the American Geophysical Union}

Paper number 4B5363.

0148-0227/86/004B-536\$05.00 loading have been the subject of many studies. Static compression studies indicate that two metastable polymorphs of calcite $\left(\mathrm{CaCO}_{3}\right)$, exist at pressures above that of the calcite-aragonite transition [Bridgman, 1939; Jamieson, 1957]. The single-crystal calcite Hugoniot shows density discontinuities at pressures of between 1.8 to 2.4 $\mathrm{GPa}$, at about $3 \mathrm{GPa}$, at about $4.5 \mathrm{GPa}$, and at about 9.5 $\mathrm{GPa}$, corresponding to the Hugoniot elastic limit (HEL) and the calcite I-II, II-III, and III-VI (see below) transitions, respectively [Ahrens and Gregson, 1964]. Analogous transitions occur in shocked limestone (polycrystalline calcite), although at somewhat lower pressures [Ahrens and Gregson, 1964; Grady et al., 1978; Grady, 1979]. The aragonite Hugoniot also displays evidence of several transitions [Vizgirda and Ahrens, 1982] which are probably unrelated to calcite II and III since aragonite is denser than these phases. Above about $10 \mathrm{GPa}$ the single-crystal calcite [Ahrens and Gregson, 1964], polycrystalline calcite [Adadurov et al., 1961; Kalashnikov et al., 1973; van Thiel et al., 1977], and single-crystal aragonite [Vizgirda and Ahrens, 1982] Hugoniots are very similar, suggesting transformation to a similar high-pressure polymorph above that pressure. In the remainder of the text we refer to this stable high-pressure polymorph as calcite VI. Calcite IV and $\mathrm{V}$ are low-pressure, high-temperature forms of $\mathrm{CaCO}_{3}$ [Carlson, 1983].

Release isentropes for polycrystalline calcite rocks shocked to pressures up to about $4 \mathrm{GPa}$ have been determined using laser in terferometry [Schuler and Grady, 1977; Grady et al., 1978; Grady, 1983] and electromagnetic particle velocity gauges [Murri et al., 1975; Larson and Anderson, 1979]. Murri et al. [1975] employed electromagnetic particle velocity gauges to determine release paths for selected carbonate rocks (porosity 0 and $15 \%$ ) shocked to between 10 and $30 \mathrm{GPa}$. In this pressure range the initial release paths lie at greater densities than the Hugoniot. Release paths for single-crystal aragonite shocked to pressures up to $40 \mathrm{GPa}$ have been determined using buffer and inclined mirror techniques [Vizgirda and Ahrens, 1982]. For shock pressures up to about $13 \mathrm{GPa}$ the release paths are steep, and maximum postshock densities are greater than the initial densities. For shock pressures between about 13 and $40 \mathrm{GPa}$ the release paths generally lie close to the Hugoniot, and maximum postshock densities are less than or equal to the initial density.

Incipient devolatilization (i.e., decomposition to $\mathrm{CaO}$ plus $\mathrm{CO}_{2}$ ) of shock-loaded calcite has been reported for shock pressures as low as $10 \mathrm{GPa}$, with significant devolatilization (greater than 50\%) occurring after shock compression to $20 \mathrm{GPa}$ [Lange and Ahrens, 1983, and unpublished manuscript, 1985]. However, other studies suggest that incipient devolatilization occurs only at pressures of $18 \mathrm{GPa}$ or higher, with only modest amounts of devolatilization (5-10\%) at pressures of 50-60 GPa [Boslough et al., 1982; Kotra et al., 1983]. Theoretical calculations of postshock energy content assuming that the release path is identical to the Hugoniot require a shock pressure of 45 $\mathrm{GPa}$ for incipient devolatilization [Kieffer and Simonds, 1980 ] and consideration of postshock entropy content assuming isentropic release [Zel'dovich and Raizer, 1967; Ahrens and O'Keefe, 1972] indicates shock pressures of at least $33 \mathrm{GPa}$ for incipient devolatilization [Vizgirda and Ahrens, 1982]. However, these previous experiments and calculations have failed to consider the effect of the 


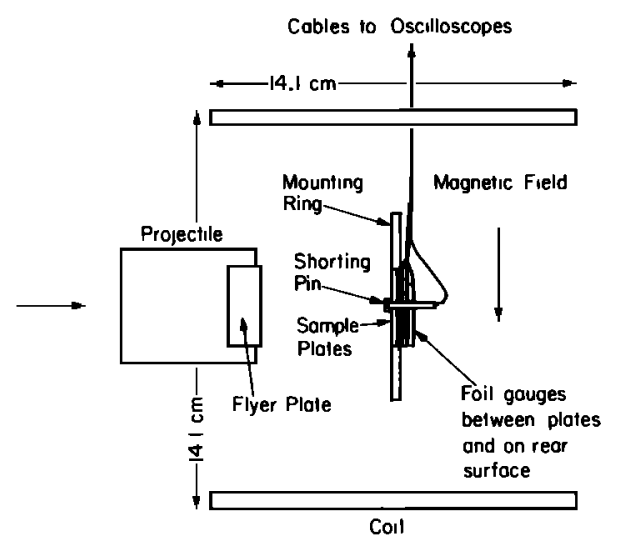

Top View

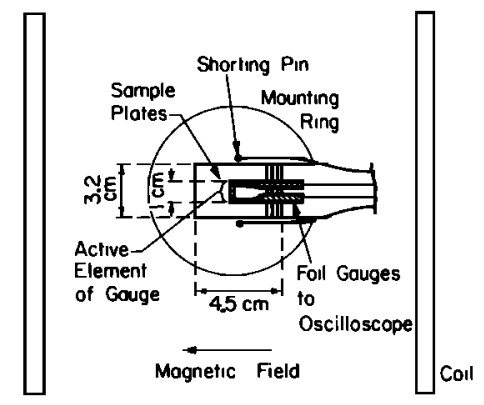

Rear View

Fig. 1. Schematic diagram of particle velocity gauge experiment. Top view, active elemeni of foil gauge is oriented in and out of plane of page. Gauges are epoxied between plates of Solenhofen limestone, and their electrical leads each go to an oscilloscope. Impact-induced velocity of gauge generates a voltage which is proportional to the magnetic field (generated by the Helmholtz coils). Pin signal triggers oscilloscopes.

ambient partial pressure of the volatile species on the equilibrium of the devolatilization reaction. The law of mass action indicates that low volatile partial pressures result in lower equilibrium temperatures for devolatilization reactions, which in turn lead to increased devolatilization for a given shock pressure.

Localization of thermal energy may also play a role in impact-induced devolatilization. A shock temperature measurement at $40 \mathrm{GPa}$ on single-crystal calcite yields a color temperature of $3700 \mathrm{~K}$, which is over twice the Hugoniot temperature calculated from continuum thermodynamic models, with an emissivity of 0.0025 [Kondo and Ahrens, 1983]. This result has been interpreted as indicating the presence of a large number of closely spaced hightemperature shear band regions immediately behind the shock front, in support of the shear instability models of Grady [1977, 1980] and Horie [1980]. These zones of intense heating would cause devolatilization to begin at much lower pressures than those calculated on the basis of continuum models.

We have determined the release paths for a slightly porous polycrystalline carbonate (Solenhofen limestone, $\rho_{0}=2.58 \mathrm{~g} / \mathrm{cm}^{3}$ ) shocked to pressures between 12 and 24 $\mathrm{GPa}$ and for a very porous calcite (Dover chalk, $\rho_{\mathrm{o}}=1.40 \mathrm{~g} / \mathrm{cm}^{3}$ ) shocked to between 5 and $11 \mathrm{GPa}$ pressure, using the electromagnetic particle velocity gauge technique. Release paths have not been previously determined for these materials shocked to these pressures. The sound velocity data obtained for the shocked state provide constraints on the mechanical strength properties under shock compression. We find that in the limestone a partial loss of shear strength occurs at shock pressures greater than about $20 \mathrm{GPa}$. This result is consistent with the concept of extensive formation of shear bands occurring in this pressure range but is not correlated with solid-solid phase transitions. The release path data are then used to evaluate a model for the postshock internal energy increase. The energy and entropy models are then employed in model equilibrium chemical calculations that demonstrate the effects of ambient $\mathrm{P}_{\mathrm{CO}_{2}}$ on impact-induced devolitilization of calcite.

\section{Experimental Technique}

The particle velocity gauge technique used in these experiments is described elsewhere in detail |Boslough,
1983 and shown schematically in Figure 1. The targets consisted of four 1.5-mm-thick plates of Solenhofen limestone with $12.5-\mu \mathrm{m}$-thick copper, polyamide-backed (Kapton, $12.5 \mu \mathrm{m}$ ) particle velocity gauges epoxied between each plate and on to the free surface. The faces of the assembled target were parallel to within $25 \mu \mathrm{m}$. Archimedean and bulk densities were determined individually for each plate. The chalk target assemblies are shown in Figure 2. In the chalk assemblies the gauges were stretched across each plate and epoxied only on a 3-mm-wide strip along the plate edge. Because the chalk is relatively weak, each target assembly consisted of only three 2- to 2.5-mm-thick plates. Additional clamping was provided by a circular clamp ring on the front and clamping strips on the rear of the mounting ring.

The target was mounted at the center of a set of Helmholtz colls so that the active element of each gauge, the incident projectile velocity, and the magnetic field generated by the coils were mutually perpendicular. Upon impact a voltage is induced across the active element of the gauge which is proportional to the effective gauge (active element) length $L$, the magnetic induction $B$, and the particle velocity $\mathrm{u}_{\mathrm{p}}$,

$$
\mathrm{V}(\mathrm{t})=\mathrm{B} \mathrm{L} \mathrm{u}_{\mathrm{p}}(\mathrm{t})
$$

where $t$ is the time after impact. $V(t)$ is in units of volts when $B$ is in gauss, $L$ is in centimeters, and $u_{p}$ is in centim-

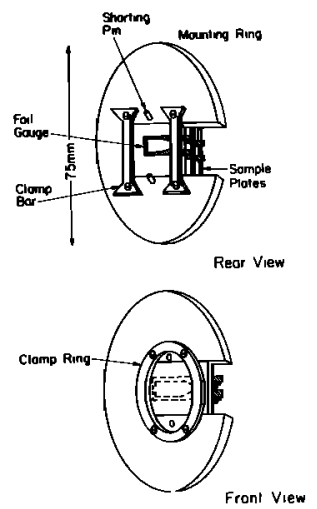

Fig. 2. Chalk (porous calcite) target assembly. Electrical leads from gauges and pins are omitted for clarity. 


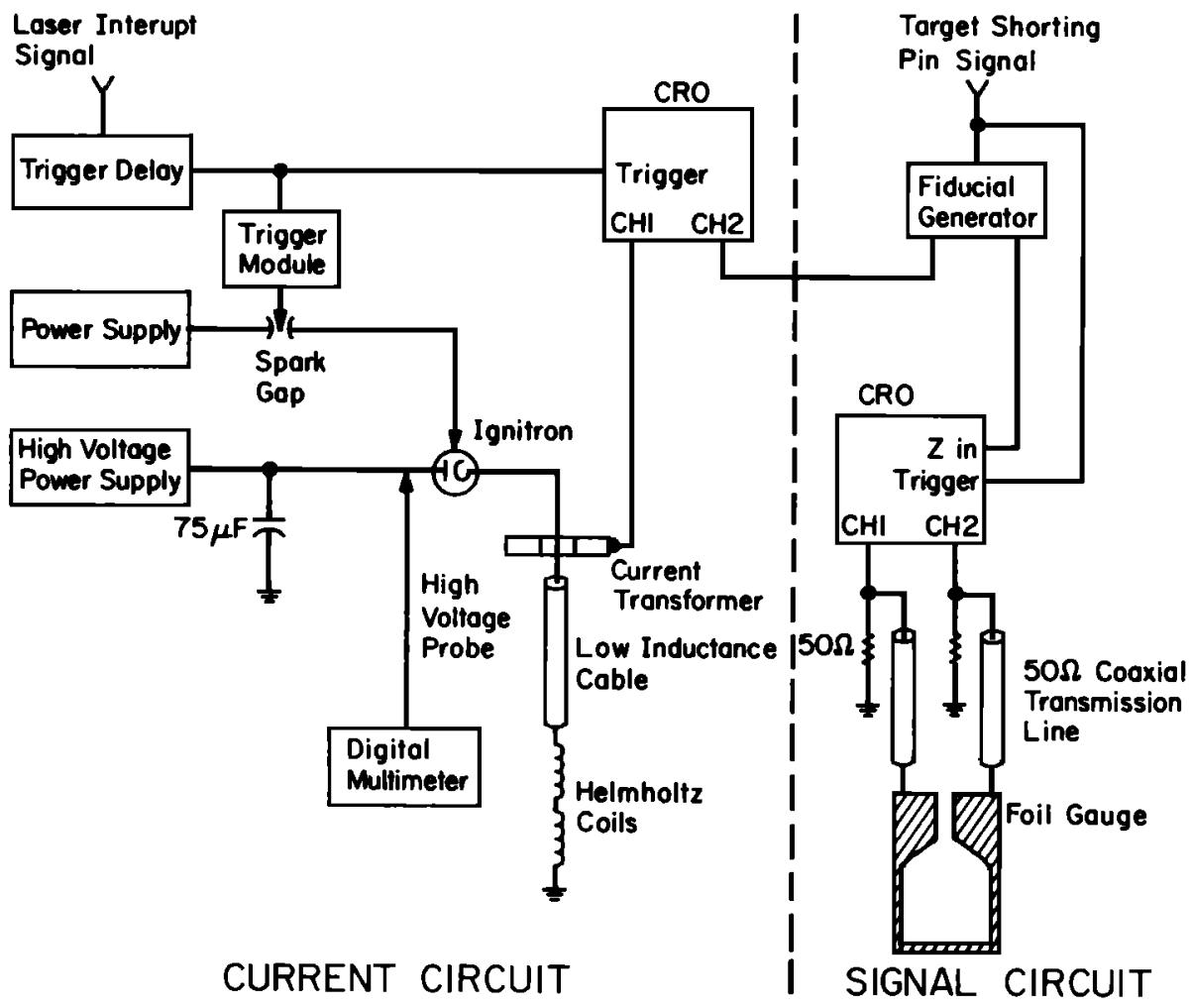

Fig. 3. Schematic diagram of current-generating and signal-measuring circuits. Only one of four signal circuits is shown.

eters per second. In these experiments, B was approximately $1.8 \mathrm{kG}$, and $\mathrm{L}$ was approximately $0.95 \mathrm{~cm}$. The gauge voltages were recorded by a series of four Tektronix oscilloscopes using the circuits sketched in Figure 3.

The shots were performed on the $40-\mathrm{mm}$ propellant gun at the California Institute of Technology [Ahrens et al., 1971]. The impact tank pressure was between 50 and 160 $\mu \mathrm{m} \mathrm{Hg}$. Fused quartz and polycrystalline alumina flyer plates between 6 and $18 \mathrm{~mm}$ thick were employed. The projectile velocity was measured by determining the flight distance of the projectile during the known time interval between two flash $\mathrm{X}$ ray photographs of the projectile.

Typical experimental results are shown in Figure 4, which shows particle velocity versus time after impact obtained from digitized oscilloscope records. The shock wave generated by the impact reaches each of the gauges in sequence (gauge 1 is nearest the impacted surface, gauge 4 is on the rear, or free, surface) accelerating it to the particle velocity of the Hugoniot state. Gauge 4 is accelerated immediately to the free surface velocity. Gauge 3 and then gauge 2 are later accelerated to higher particle velocities by the rarefaction wave propagating back into the sample from the free surface. Gange 2 is disrupted by rarefactions originating at the edges of the target before reaching the final free surface velocity. Gauge 1 is intercepted by the forward traveling rarefaction originating at the upstream side of the flyer plate and is therefore accelerated to lower particle velocities. These relationships are shown more clearly in a schematic position-time $(x-t)$ plot, shown in Figure 5.

The time interval between the shock arrival at each gauge was used to determine the shock wave velocity. This was combined with the projectile velocity and the known flyer material Hugoniot [Marsh, 1980] in an impedance match solution [McQueen et al., 1970] to yield the Hugoniot state. The Hugoniot particle velocity obtained in this way provided the reference point for the gauge voltage versus particle velocity calibration.

The stress and density along the release path are given by equations for conservation of mass and linear momentum [Cowperthwaite and Williams, 1971]:

$$
\begin{aligned}
& \left(\partial \rho / \partial \mathrm{u}_{\mathrm{p}}\right)_{\mathrm{h}}=\frac{\rho^{2}}{\rho_{\mathrm{o}}} \mathrm{C}_{\mathrm{u}} \\
& \left(\partial \sigma / \partial \mathrm{u}_{\mathrm{p}}\right)_{\mathrm{h}}=\rho_{\mathrm{o}} \mathrm{C}_{\sigma}
\end{aligned}
$$

where $\rho$ is the density, $\rho_{\mathrm{o}}$ is initial density, $u_{\mathrm{p}}$ is particle velocity, $h$ is the Lagrangian space coordinate, and

$$
\begin{aligned}
& \mathrm{C}_{\mathrm{u}}=(\partial \mathrm{h} / \partial \mathrm{t})_{\mathrm{u}} \\
& \mathrm{C}_{\sigma}=(\partial \mathrm{h} / \partial \mathrm{t})_{\sigma}
\end{aligned}
$$

where $t$ is time. $C_{u}$ is the velocity of propagation of a wave with particle velocity $u_{p}$, and $C_{\sigma}$ is the velocity of propagation of a wave of stress $\sigma$. The release waves are nonsteady simple waves [Courant and Friedrichs, 1948; Petersen et al., 1970]. Therefore $C_{u}$ and $C_{\sigma}$ are equal but depend on $u_{p}$. The digitized particle-velocity-as-a-function-of-time records were used to compute $C_{u}$ and then equations (2) and (3) were integrated numerically to obtain the stress-density path of the release. The Lagrangian sound speed, $\mathrm{C}_{u}$, is obtained using the finite difference approximation,

$$
\mathrm{C}_{\mathrm{u}} \approx \frac{\Delta \mathrm{h}}{\Delta \mathrm{t}}
$$

where $\Delta h$ is the initial distance between gauges and $\Delta t$ is the transit time for a disturbance with a particle velocity $u_{p}$. Eulerian sound speeds are equal to 


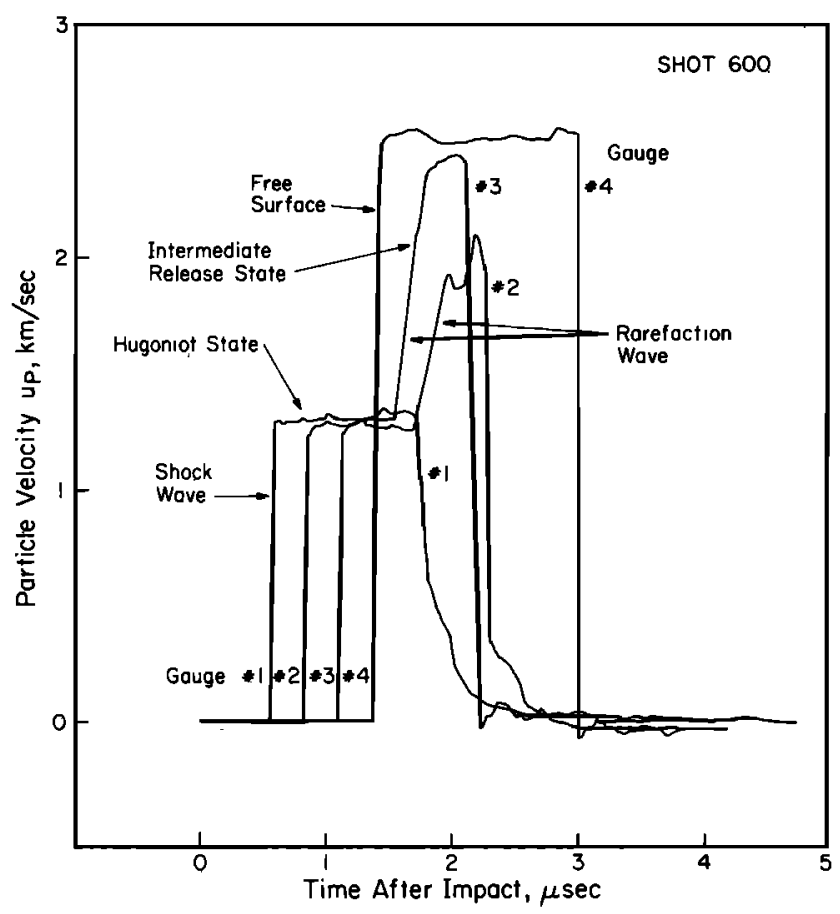

Fig. 4. Particle velocity versus time after impact for shat 600 obtained from digitized voltage versus time oscilloscope records. Gauge 1 is nearest to impacted surface, gauge 4 is at free surface. Shock velocity was $5.741 \mathrm{~km} / \mathrm{s}$, Hugoniot particle velocity was $1.319 \mathrm{~km} / \mathrm{s}$, and shock pressure was $19.75 \mathrm{GPa}$.

$$
\mathrm{C}_{\mathrm{E}}=\frac{\rho_{\mathrm{o}}}{\rho} \mathrm{C}_{\mathrm{u}}
$$

The Eulerian sound speed corresponds to the sound speed relative to the laboratory reference frame.

\section{Results}

The experimental results for the shocked states of the Solenhofep limestone and the Dover chalk are summarized in Table 1. Figures 6 and 7 are shock velocity-particle velocity $\left(\mathrm{U}_{\mathrm{s}}-\mathrm{u}_{\mathrm{p}}\right)$ and pressure-density (P- $\rho$ ) plots of the

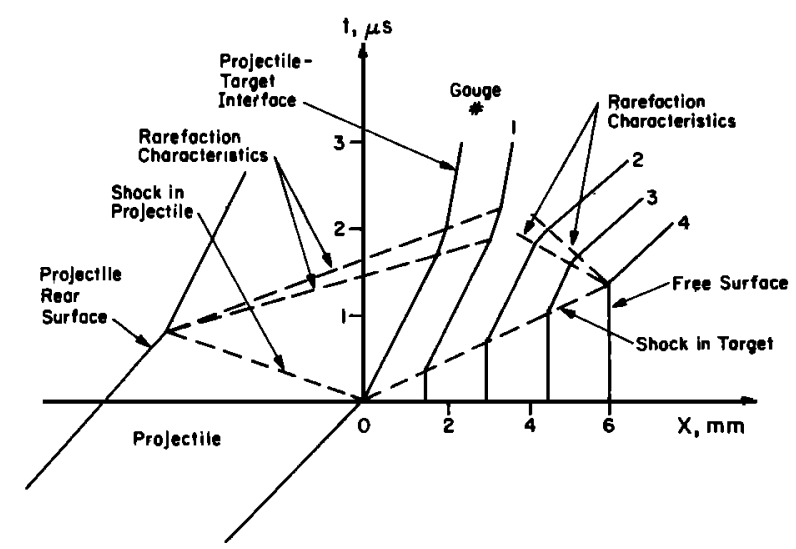

Fig. 5. Position-time ( $x-t)$ diagram of a particle velocity experiment. Projectile approaches from left and impacts stationary target at $x=0, t=0$. The diagram shows the (undesirable) case in which gauge 1 is intercepted by the rarefaction propagating forward from the projectile rear surface before arrival of rarefaction from rear surface. data, respectively. The experimental data for shot 599 (Dover chalk) appear to be erroneous. The results are listed in Table 1 but are not plotted. No release path data were obtained from shot 601 .

In two of the shots, shots 596 and 602 (Hugoniot pressures 13.10 and $11.96 \mathrm{GPa}$, respectively), multiple wave structure was observed (Figure 8). Transitions occurring between 0.36 and $0.45 \mathrm{GPa}$ and between 2.5 and $3.7 \mathrm{GPa}$ were identified. Multiple wave structure has been observed in previous shock wave experiments on carbonates and is caused by dynamic yielding and at least three additional phase changes that calcite undergoes at low pressures [Ahrens and Gregson, 1964; Grady et al., 1978]. However, in the experiments reported here the shock and particle velocities of the intermediate states are poorly constrained and are not completely consistent. These less reliable data are shown in parentheses in Table 1.

The velocity of $5.7 \pm 0.3 \mathrm{~km} / \mathrm{s}$ for the first wave of shot 602 (Table 1) is comparable to the ultrasonically determined longitudinal wave velocity of Solenhofen limestone, 5.84-5.97 km/s [Peselnick, 1962; Hughes and Cross, 1951], indicating that this transition represents the Hugoniot elastic limit (HEL). Ahrens and Gregson [1964] report elastic precursor velocities of $5.3-5.7 \mathrm{~km} / \mathrm{s}$ and a

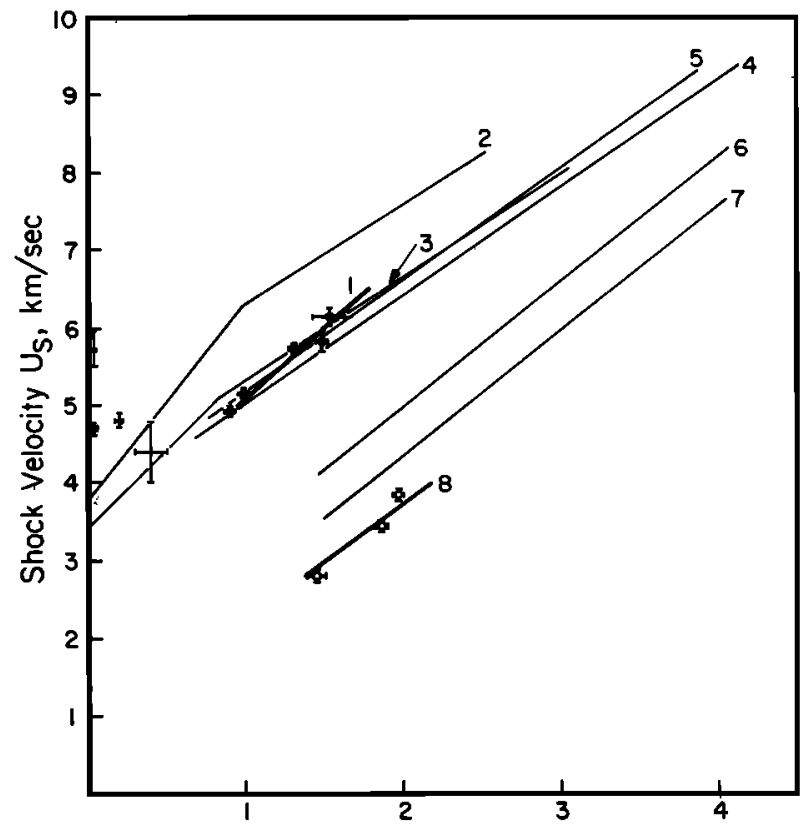

Particle Velocity $u_{p}, \mathrm{~km} / \mathrm{sec}$

Fig. 6. Shock wave velocity $U_{s}$ versus particle velocity $u_{p}$ data for experiments reported here and comparison with previous results. Filled symbols show present data for the Solenhofen limestone, open symbols show data for Dover chalk. Crosses with no symbol represent intermediate states. Lines represent fits of form $U_{s}=C_{o}+s u_{p}$. Parameters for fits are listed in Table 2. Curves are labeled as follows: 1, Solenhofen limestone, this study, $\rho_{0}$ $=2.594 ; 2$, single crystal aragonite [Vizgirda and Ahrens, 1982], $\rho_{\mathrm{o}}=2.93 ; 3$, polycrystalline calcite [Adadurov et al., 1961], $\rho_{\mathrm{o}}=2.703 ; 4$, Solenholen limestone [van Thiel et al., 1977 ], $\rho_{\mathrm{o}}=2.585 ; 5$, polycrystalline calcite [Kalashnikov et al. ${ }_{3} 1973$ ],$\rho_{\mathrm{o}}=2.665 ; 6$, polycrystalline calcite [Kalashnikov et al., 1973], $\rho_{0}=2.02 ; 7$, polycrystalline calcite [Kalashnikov et al., 1973], $\rho_{\circ}=1.705 ; 8$, Dover chalk, this study, $\rho_{\mathrm{o}}=1.40$. Units of density are grams per cubic centimeter. 
TABLE 1. Summary of Intermediate, State, Hugoniot State, and Release Path Release Transition Data

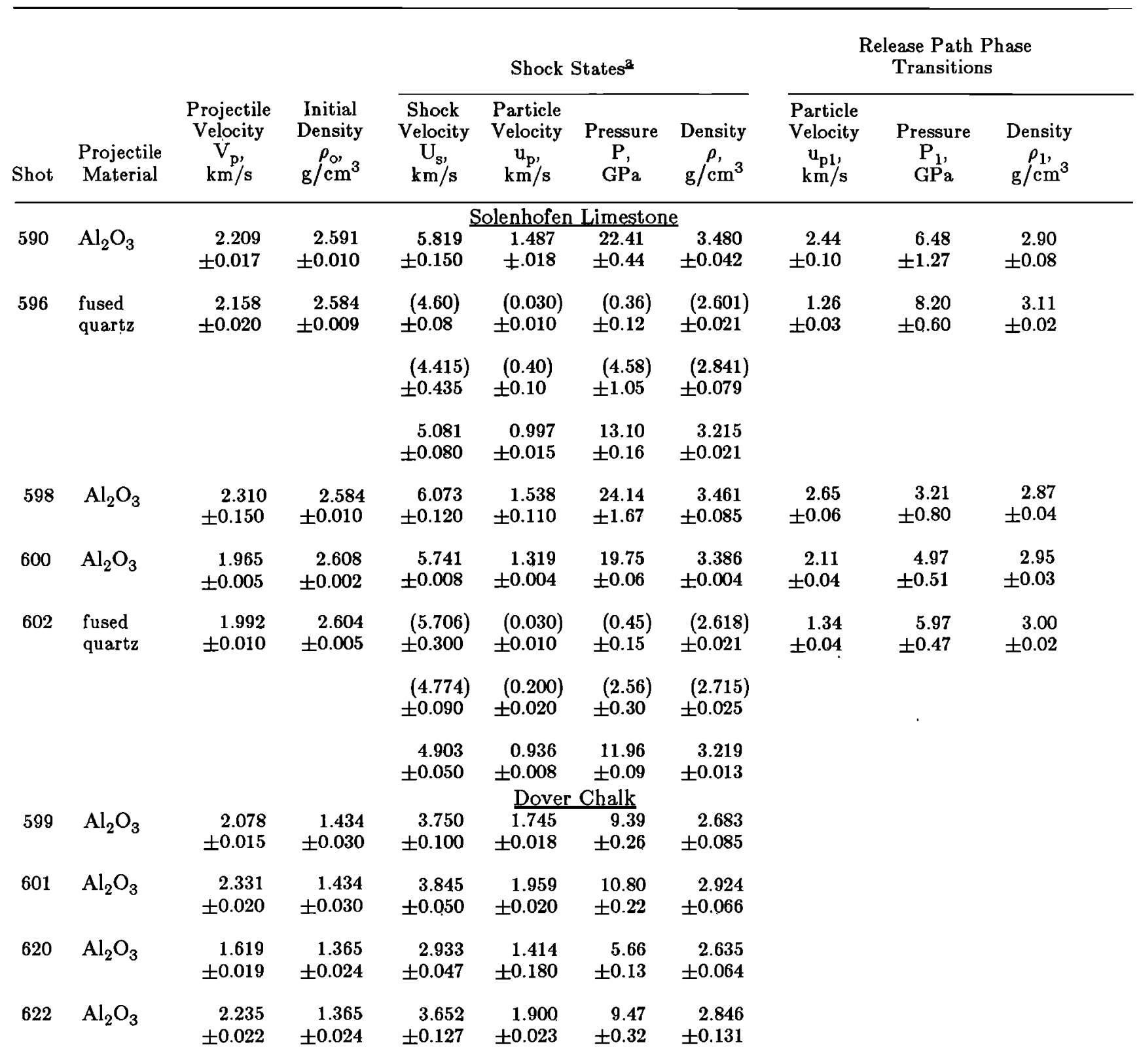

\footnotetext{
2 Highest-pressure state is final shock state. All others are ịtermediate states.
} Values in parentheses are less reliable data.

HEL of 1.0-1.5 GPa for carbonate-bearing rocks. Grady et al. [1978] report a break in the Solenhofen limestone loading wave profile at $0.6 \mathrm{GPa}$ and conclude that the calcite I-II phase transition occurs at this pressure, coincident with the onset of dynamic yielding. Our data are not of sufficient resolution in this pressure range to resolve this question. Comparison with the results of Grady et al. [1978] suggests that the transition at 2.5-3.7 GPa corresponds to the calcite II-III transition. In the higher shock pressure shots these transitions are apparently overdriven, in agreement with previous shock experimental results [Ahrens and Gregson, 1964]. No precursory waves were observed in the shots on Dover chalk.

Figure 6 shows the $U_{s}-u_{p}$ data determined in this study compared to trends observed in various calcium carbonatebearing rocks and minerals by previous investigators. For
Solenhofen limestone the valtes of $\mathrm{U}_{\mathrm{s}}$ and $\mathrm{u}_{\mathrm{p}}$ lie within the range of values previously determined by other investigators, but the slope of the line defined by the data is greater. The data in the range of 12 to $24 \mathrm{GPa}$ can be fit by an equation of the form

$$
\mathrm{U}_{\mathrm{s}}=\mathrm{C}_{\mathrm{o}}+\mathrm{s} \mathrm{u}_{\mathrm{p}}
$$

where $\mathrm{C}_{\mathrm{o}}$ and $\mathrm{s}$ are constants, with $\mathrm{C}_{\mathrm{o}}=3.269 \mathrm{~km} / \mathrm{s}$ and $\mathrm{s}$ $=1.796\left(\mathrm{r}^{2}=0.97\right)$. Previously determined values of $\mathrm{C}_{\mathrm{o}}$ and $\mathrm{s}$ range from 3.62 to $3.99 \mathrm{~km} / \mathrm{s}$ and 1.32 to 1.61 , respectively, and are summarized in Table 2. The $\mathrm{U}_{\mathrm{s}}-\mathrm{u}_{\mathrm{p}}$ data for Dover chalk, $\rho_{o}=1.40 \mathrm{~g} / \mathrm{cm}^{3}$, can be fit with $\mathrm{C}_{0}=0.667$ and $\mathrm{s}=1.598\left(\mathrm{r}^{2}=0.989\right)$. This line is consistent with the trend formed by the porous calcite results of Kalashnikov et al. [1973]. 


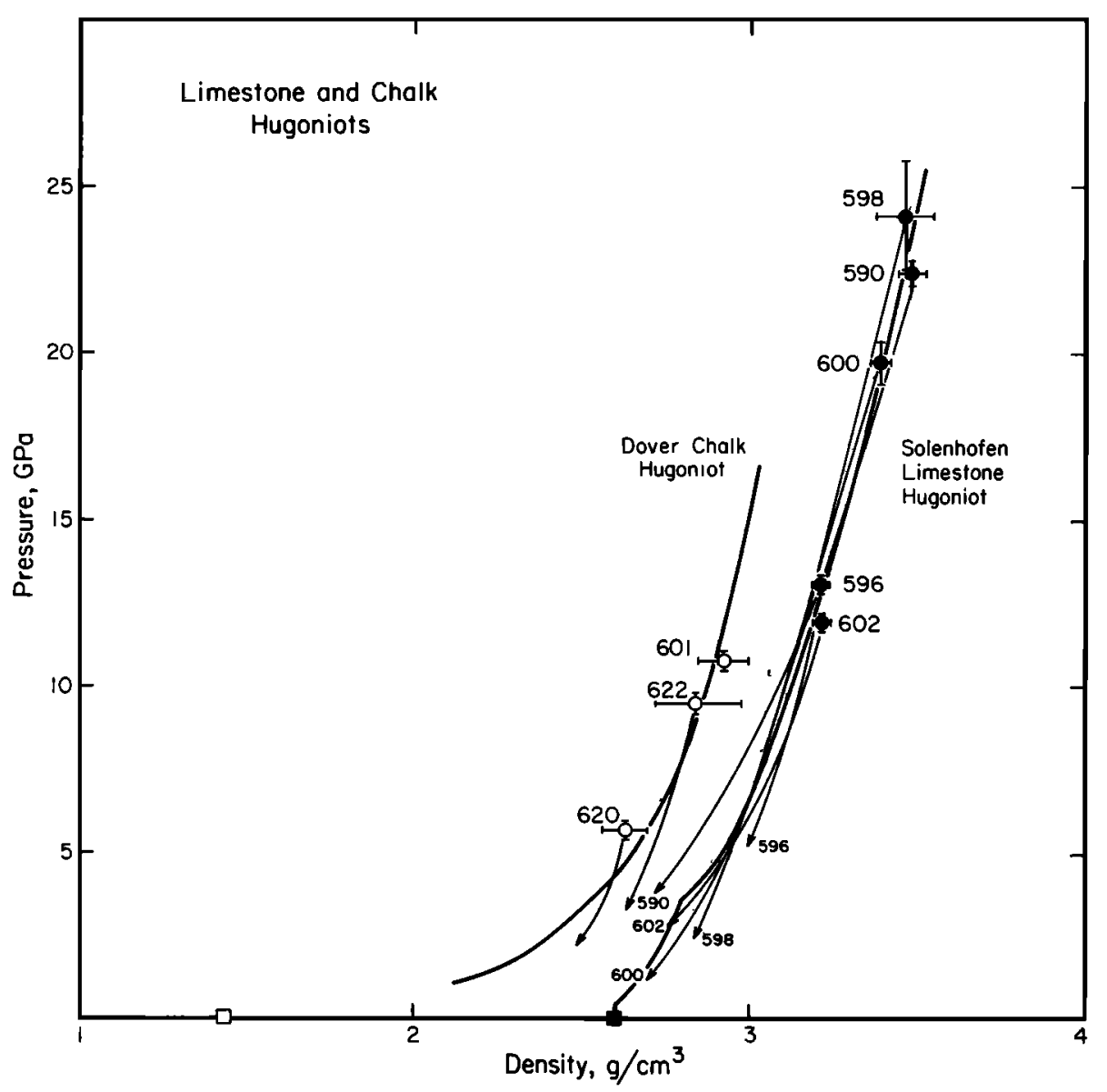

Fig. 7. Hugoniat states and release paths for Solenhofen limestone and Dover chalk. Solid symbols are for Solenhofen limestone; open symbols are for Dover chalk, squares represent initial densities. Heavy solid lines are fits to data (Table 2).

As shown in Figures 4 and 8 , the slopes of the particle velocity records of all the Solenhofen limestone shots exhibit a discontinuity during release. The pressures and densities at which the discontinuity occurs for each shot are listed in Table 1 . The data are somewhat scattered but the transition occurs at about $5.5 \pm 2.5 \mathrm{GPa}$, and no trend with peak stress level is apparent. Previous observations of a phase transition upon release in calcite shocked up to 5 GPa have been attributed to the calcite III-II transition [Grady et al., 1978]. Rarefaction shocks have been observed in calcite shocked to between 18 and $31 \mathrm{GPa}$ [Murri et al, 1975; Grady and Moody, 1985]. Rarefaction shocks are not evident in the particle velocity records reported here. However, the pressures behind the rarefaction shocks reported by the previous investigators correspond roughly to the stress levels at which we observe the particle velocity slope discontinuities. We thus interpret the discontinuities as indicating a high-pressure (calcite VI) to lowpressure (unspecified) polymorphic transition during the release.

The initial release paths for Solenhofen limestone plotted in Figure 7 lie near the Hugoniot, but at slightly higher densities, for all shock pressures studied. The particle velocity records do not give complete information down to zero pressure due to disruption of the foil gauges by rarefactions propagating inward from the sample edges. Extrapolation to zero-pressure yields complete release densities between 2.59 and $2.81 \mathrm{~g} / \mathrm{cm}^{3}$. In contrast to the behavior for Solenhofen limestone reported here, previously reported release paths for single crystal aragonite vary significantly

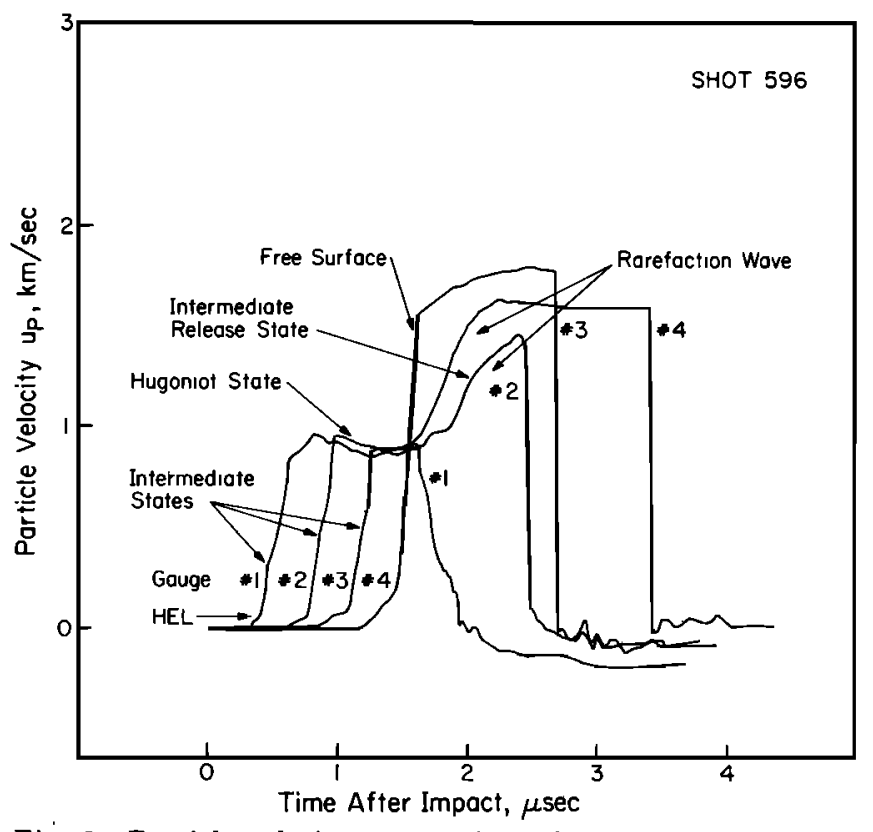

Fig. 8. Particle velocity versus time after impact for shot 596 (Solenhofen limestone, 13.1 GPa), showing multiple shock fronts on leading edge of record (including HEL) and indicating presence of an intermediate release state during unloading. 
TABLE 2. Summary of Polycrystalline Calcite Hugoniot Data

\begin{tabular}{|c|c|c|c|c|c|}
\hline Material & Reference & $\rho_{0}, \mathrm{~g} / \mathrm{cm}^{3}$ & $\mathrm{C}_{\mathrm{o}}, \mathrm{km} / \mathrm{s}$ & $\bar{s}$ & $\begin{array}{c}\text { Pressure Range, } \\
\text { GPa }\end{array}$ \\
\hline Solenhofen limestone & this work & 2.594 & 3.269 & 1.796 & $12-24$ \\
\hline Dover chalk & this work & 1.40 & 0.67 & 1.60 & $5-11$ \\
\hline Polycrystalline calcite & Adadurov et al., 1961 & 2.703 & $\begin{array}{l}3.40 \\
3.99\end{array}$ & $\begin{array}{l}2.00 \\
1.32\end{array}$ & $\begin{array}{r}5-13 \\
13-51\end{array}$ \\
\hline Polycrystalline calcite & Kalashnikov et al., 1973 & $\begin{array}{l}2.665 \\
2.020 \\
1.705\end{array}$ & $\begin{array}{l}3.70 \\
1.74 \\
1.15\end{array}$ & $\begin{array}{l}1.44 \\
1.61 \\
1.60\end{array}$ & $\begin{array}{l}10-94 \\
13-71 \\
10-59\end{array}$ \\
\hline Solenhofen limestone & van Thiel et al., 1977 & 2.585 & 3.62 & 1.39 & $8-90$ \\
\hline
\end{tabular}

with shock pressure. For shock pressures between about 10 and $15 \mathrm{GPa}$ the aragonite release paths are very steep, with complete release densities (determined via inclined mirror experiments) equal to or greater than the initial density. For shock pressures greater than about $20 \mathrm{GPa}$, the release paths approximate the Hugoniot, with complete release densities equal to or less than the initial density [Vizgirda and Ahrens, 1982]. Release paths for Solenhofen limestone [Schuler and Grady, 1977] and other carbonate rocks [Grady et al., 1976; Grady, 1983] shocked to pressures up to about $5 \mathrm{GPa}$ generally follow the Hugoniot, with extrapolated complete release densities approximately equal to the initial density.

The release paths for Dover chalk lie at higher densities than the Hugoniot. The extrapolated complete release densities lie between 2.44 and $2.55 \mathrm{~g} / \mathrm{cm}^{3}$. Eulerian sound speeds for the shocked states were calculated according to equations 5 and 6 and are plotted in Figure 9.

\section{Discussion}

\section{Sound Speeds and Shear Strength}

Properties of calcite VI, reached at about $10 \mathrm{GPa}$ shock pressure, have been deduced by Vizgirda and Ahrens [1982] and are listed in Table 3 . The zero-pressure bulk sound velocity

$$
\mathrm{V}_{\phi}=\left(\mathrm{K}_{\mathrm{os}} / \rho_{\mathrm{o}}\right)^{1 / 2}
$$

where $K_{o s}$ is the zero-pressure isentropic bulk modulus, is between about 5.00 and $5.54 \mathrm{~km} / \mathrm{s}$ at $300 \mathrm{~K}$. Assuming a Poisson's ratio $\sigma$ of 0.25 we obtain a zero-pressure, $300 \mathrm{~K}$ compressional velocity $V_{p}$ of between 6.46 and $7.15 \mathrm{~km} / \mathrm{s}$ using the relationship

$$
\mathrm{V}_{\mathrm{p}}=\left\{\mathrm{K}_{\mathrm{os}} / \rho \cdot[1+2(1-2 \sigma) /(1+\sigma)]\right\}^{1 / 2}
$$

We can compare the observed Hugoniot sound velocities with compressional wave velocities $V_{p}$ along an isentrope for calcite VI using finite strain theory [Sammis et al., 1970] (see also Burdick and Anderson [1975]). Thus

$$
\begin{gathered}
\mathrm{V}_{\mathrm{p}}^{2}(\rho)=\mathrm{V}_{\mathrm{p}, \mathrm{o}}^{2}(1-2 \epsilon)\left[1-2 \epsilon\left(3 \mathrm{D}_{\mathrm{p}}-1\right)\right] \\
\mathrm{V}_{\mathrm{s}}^{2}(\rho)=\mathrm{V}_{\mathrm{s}, \mathrm{o}}^{2}(1-2 \epsilon)\left[1-2 \epsilon\left(3 \mathrm{D}_{\mathrm{s}}-1\right)\right]
\end{gathered}
$$

and

$$
\mathrm{P}=-3 \mathrm{~K}_{\mathrm{os}} \epsilon(1-2 \epsilon)^{5 / 2}(1+2 \epsilon \xi) .
$$

The volumetric strain $\epsilon$ is

$$
\epsilon=\left[1-\left(\rho / \rho_{\mathrm{o}}\right)^{2 / 3}\right] / 2
$$

the finite strain parameter $\xi$ is

$$
\begin{gathered}
\xi=3\left[4-\left(d K_{o s} / d P\right)_{s}\right] / 4 \\
D_{p}=K_{o s} d l n V_{p} / d P
\end{gathered}
$$

and

$$
\mathrm{D}_{\mathrm{s}}=\mathrm{K}_{\mathrm{os}} \mathrm{d} l \boldsymbol{l n} \mathrm{V}_{\mathrm{s}} / \mathrm{d} \mathrm{P}
$$

No detêrminations of $D_{p}$ and $D_{s}$ for calcite VI exist. For many minerals, $D_{p}$ lies in the range $1.0 \leq D_{p} \leq 1.6$, and $\mathrm{D}_{\mathrm{q}}$ lies between $0.1 \leq \mathrm{D}_{\mathrm{s}} \leq 1.0$ [Anderson et al., 1968; Sammis et al., 1970]. This range of values was used in computing $\mathrm{V}_{\mathrm{p}}(\rho)$ and $\mathrm{V}_{\mathrm{s}}(\dot{\rho})$. The variation of bulk sound speed $V_{\phi}$ along an isentrope is given by

$$
\mathrm{V}_{\phi}^{2}(\rho)=\mathrm{V}_{\mathrm{p}}(\rho)^{2}-4 \mathrm{~V}_{\mathrm{s}}^{2}(\rho) / 3
$$

The effect of temperature on sound velocity is small. The temperature on the Hugoniot $\mathrm{T}_{\mathrm{H}}$ was calculated using the relation

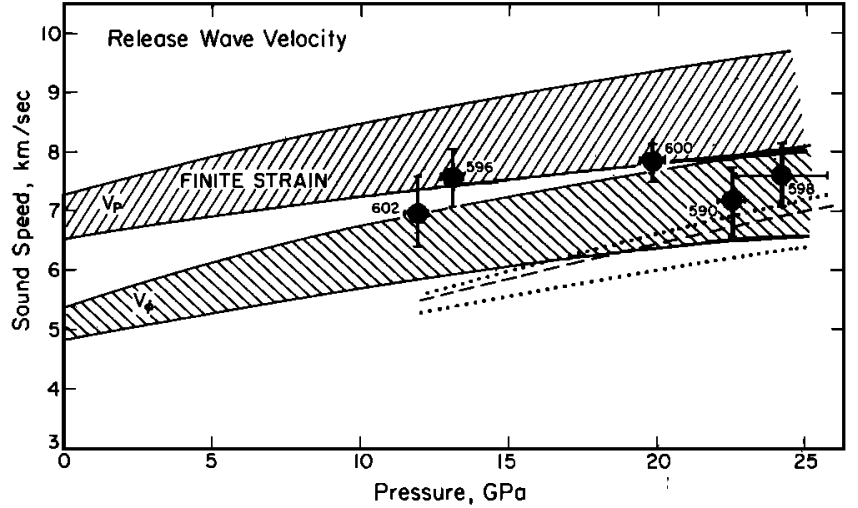

Fig. 9. Eulerian sound speeds, $C_{E}$, on the Hugoniot of shocked Solenhofen limestone. Ranges of compressional wave velocity $V_{p}$ and bulk sound speed $V_{\phi}$ for calcite VI are computed using Eulerian finite strain theory (see text) and parameters listed in Table 3. Values plotted are for an isentrope originating at $750 \mathrm{~K}$ at zero pressure. Dashed line is $\mathrm{V}_{\phi}$ alon the Hugoniot of calcite VI calcular according to equation (19) using equation of state parameters determined in this work (Table 2) and Gruneisen parameter $\gamma$ given in Table 3 . Dotted lines show effect of a factor of 2 variation in $\gamma$. 
TABLE 3. Properties of the Calcite Polymorphs

\begin{tabular}{lccccc}
\hline Property & Symbol (Units) & I & II & III & VI \\
\hline STP density $(300 \mathrm{~K})$ & $\rho_{\mathrm{o}}\left(\mathrm{g} / \mathrm{cm}^{3}\right)$ & $2.71^{\mathrm{a}}$ & $2.71^{\mathrm{a}}$ & $2.71^{\mathrm{a}}$ & $3.0-3.1^{\mathrm{b}}$ \\
Isentropic bulk modulus & $\mathrm{K}_{\mathrm{os}}(\mathrm{GPa})$ & $71.1^{\mathrm{a}}$ & $14.7^{\mathrm{a}}$ & $51.7^{\mathrm{a}}$ & $75-95^{\mathrm{b}}$ \\
$\mathrm{dK} / \mathrm{dP}$ & $\mathrm{K}$ & $4.15^{\mathrm{a}}$ & $4.62^{\mathrm{a}}$ & $8.28^{\mathrm{a}}$ & $4.1-3.5^{\mathrm{b}}$ \\
Transition energy & $\mathrm{E}_{\mathrm{tr}}(\mathrm{J} / \mathrm{g})^{\mathrm{c}}$ & 0 & - & - & $200-20^{\mathrm{b}}$ \\
Transition entropy & $\mathrm{S}_{\mathrm{tr}}(\mathrm{J} / \mathrm{g} \mathrm{K})^{\mathrm{c}}$ & 0 & - & - & -0.101 \\
Gruneisen parameter & $\gamma$ & $1.5\left(\mathrm{~V} / \mathrm{V}_{\mathrm{o}}\right)^{\mathrm{d}}$ & $1.5\left(\mathrm{~V} / \mathrm{V}_{\mathrm{o}}\right)^{\mathrm{d}}$ & $1.5\left(\mathrm{~V} / \mathrm{V}_{\mathrm{o}}\right)^{\mathrm{d}}$ & $1.5\left(\mathrm{~V} / \mathrm{V}_{\mathrm{o}}\right)^{\mathrm{d}}$ \\
Poisson's ratio & $\sigma$ & $0.25^{\mathrm{d}}$ & $0.25^{\mathrm{d}}$ & $0.25^{\mathrm{d}}$ & $0.25^{\mathrm{d}}$ \\
$\mathrm{K}_{\mathrm{os}} \cdot \mathrm{d} \ln \mathrm{V}_{\mathrm{p}} / \mathrm{dP}$ & $\mathrm{D}_{\mathrm{p}}$ & $2.13^{\mathrm{e}}$ & $0.44^{\mathrm{e}}$ & $1.55^{\mathrm{e}}$ & $1.0-1.6^{\mathrm{f}}$ \\
$\mathrm{K}_{\mathrm{os}} \cdot \mathrm{d}$ ln $\mathrm{V}_{\mathrm{s}} / \mathrm{dP}$ & $\mathrm{D}_{\mathrm{s}}$ & $2.13^{\mathrm{e}}$ & $0.44^{\mathrm{e}}$ & $1.55^{\mathrm{e}}$ & $1.0-0.1^{\mathrm{f}}$ \\
$\mathrm{d} \mathrm{V}_{\mathrm{p}} / \mathrm{dT}$ & $(\mathrm{km} / \mathrm{s} \mathrm{K})$ & $-3.3 \times 10^{-4 \mathrm{f}}$ & $-3.3 \times 10^{-4 \mathrm{f}}$ & $-3.3 \times 10^{-4 \mathrm{f}}$ & $-3.3 \times 10^{-4 \mathrm{f}}$ \\
$\mathrm{d} \mathrm{V}_{\mathrm{s}} / \mathrm{dT}$ & $(\mathrm{km} / \mathrm{s} \mathrm{K})$ & $-2.4 \times 10^{-4} \mathrm{f}$ & $-2.4 \times 10^{-4} \mathrm{f}$ & $-2.4 \times 10^{-4} \mathrm{f}$ & $-2.4 \times 10^{-4} \mathrm{f}$ \\
Specific heat & $\mathrm{C}_{\mathrm{v}}(\mathrm{J} / \mathrm{g} \mathrm{K})$ & $1.25^{\mathrm{g}}$ & $1.25^{\mathrm{g}}$ & $1.25^{\mathrm{g}}$ & $1.25^{\mathrm{g}}$ \\
\hline
\end{tabular}

a Singh and Kennedy [1974].

b Vizgirda and Ahrens [1982].

c Relative to calcite I at $298 \mathrm{~K}, 1$ bar

d Assumed.

e Peselnick and Wilson [1968] and Wang and Meltzer [1973].

f Anderson et al. [1968] and Sammis et al. [1970].

g Dulong-Petit value, $\mathrm{T} \geq 650$ [Vizgirda and Ahrens, 1982]; at lower temperatures $\mathrm{C}_{\mathrm{p}}$ of calcite given by Robie et al. [1978].

$$
\begin{aligned}
\mathrm{T}_{\mathrm{H}}= & 298 \exp \left[-\int_{\mathrm{V}_{0}^{\prime}}^{\mathrm{V}_{\mathrm{H}}} \frac{\gamma}{\mathrm{V}} \mathrm{dV}\right] \\
& +\left[\frac{1}{2}\left(\mathrm{P}_{\mathrm{O}}+\mathrm{P}_{\mathrm{H}}\right)\left(\mathrm{V}_{\mathrm{O}}-\mathrm{V}_{\mathrm{H})}+\int_{\mathrm{V}_{\mathrm{o}}^{\prime}}^{\mathrm{V}_{\mathrm{H}}}(\mathrm{PdV})_{\mathrm{s}}\right] / \mathrm{C}_{\mathrm{V}}\right.
\end{aligned}
$$

where $\gamma$ is the Gruneisen parameter and $C_{y}$ is the heat capacity at constant volume. $V_{O}$ refers to the initial volume of the experimentally shocked material, whereas $V_{O}^{\prime}$ is the volume at standard temperature and pressure (STP) conditions of the high-pressure polymorph, calcite VI. The energy of transition $E_{t r}$ does not enter into the temperature calculation because, in performing the calculation, the calcite I to VI transition occurs isothermally at STP. The first term on the right-hand side of equation (18) is the temperature increase between $V_{O}^{\prime}$ and $V_{H}$ along the calcite VI adiabat, and the second term represents the temperature increase in going from the adiabat to the Hugoniot isochorically at $\mathrm{V}_{\mathrm{H}}$. The parameters used for the calculation of $\mathrm{T}_{\mathrm{H}}$ are listed in Table 3. For the Dover chalk, the temperatures are sufficiently high that calculated Hugoniot temperatures are relatively insensitive to the specific isentrope employed in the calculation. Assuming a value of $(\mathrm{d} \mathrm{V} / \mathrm{dT})_{\mathrm{p}}$ of $-3.3 \times 10^{-4} \mathrm{~km} / \mathrm{s} \mathrm{K}$ (values tabulated by Anderson et al. [1968] range from about $-1.5 \mathrm{x}$ $10^{-4}$ to $-5.2 \times 10^{-4} \mathrm{~km} / \mathrm{s} \mathrm{K}$ ), an increase in the initial temperature of $450 \mathrm{~K}$ results in a $V_{p}$ decrease of $0.15 \mathrm{~km} / \mathrm{s}$. $\left(\mathrm{dV}_{\mathrm{s}} / \mathrm{dT}\right)_{\mathrm{p}}$ is estimated to be about $-2.4 \times 10^{-4} \mathrm{~km} / \mathrm{s} \mathrm{K}$ [Anderson et al., 1968].

The range of values of $V_{p}$ and $V_{\phi}$ along a $750 \mathrm{~K}$ isen- trope calculated using the parameters listed in Table 3 is shown in Figure 9. Although the calculated bulk and compressional sound speeds are poorly constrained, the data indicate that the measured initial release wave speed is equal to that of the compressional wave velocity for shock pressures up to about $20 \mathrm{GPa}$. In other words, calcite VI retains its shear strength in the shocked state up to this pressure. At the highest pressures attained, 22-24 GPa, a loss of strength in the shocked state may occur.

The bulk sound speed $V_{\phi}$ at the Hugoniot may also be calculated from the shock wave equation of state (equation (7)) and a model for the Gruneisen parameter $\gamma$, using the relationship

$$
\mathrm{V}_{\phi}=\mathrm{V}_{\mathrm{H}}\left\{\frac{\mathrm{dP}}{\mathrm{dV}} \mathrm{I}_{\mathrm{H}}\left[\left(\mathrm{V}_{\mathrm{o}}-\mathrm{V}_{\mathrm{H}}\right) \frac{\gamma}{2 \mathrm{~V}_{\mathrm{H}}}-1\right]+\mathrm{P}_{\mathrm{H}} \gamma / 2 \mathrm{~V}_{\mathrm{H}}\right\}^{1 / 2}
$$

[McQueen et al., 1967] where $V_{0}$ is the initial sample volume, $V_{H}$ is the Hugoniot volume, and $\mathrm{dP} /\left.\mathrm{dV}\right|_{H}$ is the slope of the Hugoniot. We use the relationship $\gamma=\gamma_{o}\left(\rho_{\mathrm{o}} / \rho\right)^{\mathrm{n}}$ where $\gamma_{\mathrm{o}}=1.5$ and $\mathrm{n}=1.0$ [Vizgirda and Ahrens, 1982] (Table 3). This curve is plotted as a dashed line in Figure 9 and supports the conclusion that at least a partial loss of shear strength occurs at a pressure of 22-24 GPa. A variation in $\gamma$ of a factor of 2 from the above value does not change the conclusion (dotted lines in Figure 9).

The Eulerian sound speeds along the release paths of the shocked Dover chalk are plotted in Figure 10. At the relatively low shock pressures and high continuum temperatures reached in these experiments it is unlikely that the starting material transformed to calcite VI. However, it is not known which of the three calcite low-pressure 


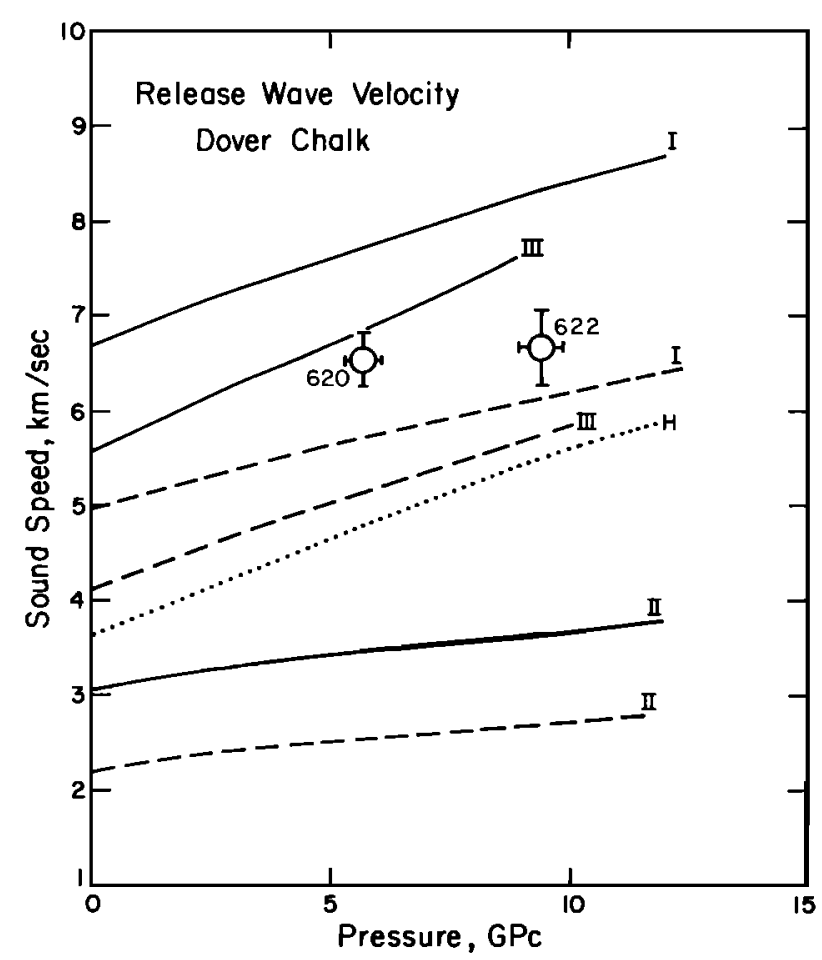

Fig. 10. Eulerian sound speeds $C_{E}$ on Hugoniot of Dover chalk. Solid and dashed lines represent compressional wave velocities and bulk sound velocities, respectively, of calcite polymorphs along isentropes centered at $750 \mathrm{~K}$ and ambient pressure, calculated using the parameters in Table 3. Roman numerals refer to the assumed calcite polymorph. Dotted line labeled $H$ represents bulk sound speed along low-pressure (5-13 GPa) polycrystalline calcite Hugoniot of Adadurov et al. [1961] (Table 2) using equation (19).

polymorphs exists in the shocked state. We have therefore plotted the bulk and compressional wave velocities for calcite I, II, and III using, for comparison, the data of Singh and Kennedy [1974], assuming that Poisson's ratio $\sigma=$ 0.25 [Anderson et al., 1968; Grady et al., 1978]. Also plotted is the bulk sound speed in the shocked state calculated using the low pressure (5-13 GPa) polycrystalline calcite Hugoniot of Adadurov et al. [1961] and equation (19). The data for shots 620 and 622 plot between the bulk and compressional wave velocities for calcite I and III, but the result for shot $622\left(\mathrm{P}_{\mathrm{H}}=9.47 \mathrm{GPa}\right)$ lies nearer the bulk sound speed of calcite I and III.

An alternative approach is to assume that the measured initial release wave velocities correspond to the bulk sound speeds, then to calculate $\gamma$ using equation (19). However, the values of $\gamma$ calculated this way are less than zero for all the shots in both materials, save one (shot 590, Solenhofen limestone, 22.4 GPa, yields $\gamma=0.23$ ). These nonphysical results are a further indication that the measured release wave velocities are compressional wave velocities and that Solenhofen limestone and Dover chalk retain their shear strength in the Hugoniot state. The intermediate value of $\gamma$ at $22.4 \mathrm{GPa}$ for the Solenhofen limestone is an indication of at least a partial loss of shear strength.

Retention of shear strength in the shocked state has been documented for several materials, for example, $\mathrm{Al}_{2} \mathrm{O}_{3}$ shocked to $40 \mathrm{GPa}$ [Bless and Ahrens, 1976], $\mathrm{MgO}$ to 12 $\mathrm{GPa}$ [Grady, 1977], and anorthosite to $10 \mathrm{GPa}$ [Boslough and Ahrens, 1985]. Loss of shear strength in materials shocked to pressures lower than those required for bulk melting of the sample has been reported for quartz shocked to 15-40 GPa [Grady et al., 1975] and for calcite rocks to about $5 \mathrm{GPa}$ [Grady et al., 1978]. Both quartz and calcite undergo solid-solid phase transitions throughout these pressure ranges. In these materials, the loss of shear strength is apparently caused by the occurrence of molten "shear bands" caused by localization of thermal energy under shock compression. The rates of the solid-solid phase transitions are enhanced by the existence of, and high temperatures in, the molten regions [Grady et al., 1975; Grady, 1980]. The reduction of shear strength of Solenhofen limestone at 22-24 GPa indicates that extensive shear band formation can occur in the absence of bulk solid-solid phase transformation. The measured color temperature (shear band temperature) of $2455 \mathrm{~K}$ at $22 \mathrm{GPa}$ (D. Schmitt, personal communication, 1984) supports this conclusion. Thus the occurrence of solid-solid phase transitions under shock implies thermal energy localization (shear bands), but the existence of shear bands (as indicated by loss of shear strength and by very high color temperatures) is not an indication of, nor is it dependent on, solid-solid transitions.

\section{Impact-Induced Devolatilization}

Recent shock recovery experiments on single crystal calcite have given differing results for the extent of impactinduced devolatilization as a function of shock pressures. The process under discussion can be described by the reaction

$$
\mathrm{CaCO}_{3(\mathrm{I})} \rightarrow \text { impact, release } \rightarrow \mathrm{CaO}_{(\mathrm{s})}+\mathrm{CO}_{2} \text { (gas) }
$$

The gas recovery experiments of Boslough et al. [1982] indicated that incipient devolatilization (0.03-0.3\% devolatilization) occurred at a shock pressure of $18 \mathrm{GPa}$. Solid recovery experiments by Lange and Ahrens [1983] resulted in roughly $30-40 \%$ devolatilization at $20 \mathrm{GPa}$, with incipient devolatilization occurring at less than $10 \mathrm{GPa}$. Solid recovery experiments by Kotra et al. [1983] yielded very little devolatilization, only 5-10\% devolatilization took place at shock pressures up to 50-60 GPa. In the following sections we compare these experimentally determined values of the fraction of $\mathrm{CO}_{2}$ volatilized with calculations based on postshock energy and entropy content.

The energy imparted to a material upon shock compression $E_{H}$ relative to the energy of the initial state $E_{O}$ is

$$
E_{H}-E_{o}=\frac{1}{2}\left(P_{H}+P_{o}\right)\left(V_{o}-V_{H}\right)+E_{t r}
$$

where $E_{\mathrm{tr}}$ is the energy of transition from the low pressure to the high-pressure polymorph (if such a transition occurs). The energy released upon relaxation to zero pressure $\mathrm{E}_{\mathrm{rel}}$ is

$$
\mathrm{E}_{\mathrm{rel}}-\mathrm{E}_{\mathrm{H}}=-\int_{\mathrm{V}_{\mathbf{H}}}^{\mathrm{v}_{\mathbf{0}}} \mathrm{P}_{\mathrm{s}} \mathrm{dV}+\mathrm{E}_{\mathrm{tr}}^{\prime}
$$

where $V_{\infty}$ is the complete release volume, the integral is taken along the appropriate (see below) isentrope, and $E_{t r}^{\prime}$ is the energy of phase changes that occur during release (see below). The total post-shock energy $E_{p}$ (relative to the initial energy content $E_{o}$ ) is the sum

$$
E_{p}-E_{o}=\left(E_{H}-E_{o}\right)+\left(E_{r e l}-E_{H}\right)
$$

The release paths for the shots reported here can be in tegrated directly (with extrapolation to zero pressure) to yield the first term on the right-hand side of equation (22). In addition, the particle velocity records indicate that a phase transition occurs a.t some pressure greater than zero upon release, although the precise nature of the phase change is uncertain (see results section). For simplicity, we assume that the transition involved is from the calcite VI poly morph back to calcite I. Thus $\mathrm{E}_{\mathrm{tr}}=-\mathrm{E}_{\mathrm{tr}}^{\prime}$, and 


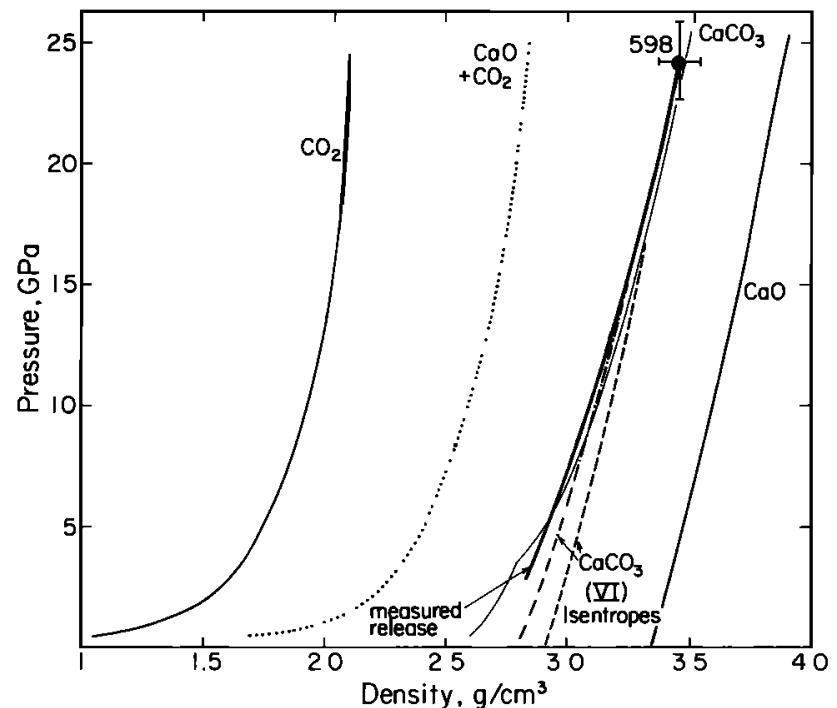

Fig. 11. Measured release path for Solenhofen limestone shocked to $24 \mathrm{GPa}$ (shot 598), heavy line, relative to isentropic release of calcite VI; dashed line, $\mathrm{K}=95 \mathrm{GPa}, \mathrm{K}^{\prime}$ $=3.5$; dash-dot line, $\mathrm{K}=75 \mathrm{GPa}, \mathrm{K} 4.1 \mathrm{GPa}$. Lines " $\mathrm{CaO}$ " and " $\mathrm{CaCO}_{3}$ " are Hugoniots ( $\mathrm{CaO}$ Hugoniot, $\mathrm{B} 1$ phase (Jeanloz and Ahrens, 1980]). Line " $\mathrm{CO}_{2}$ " is the density of $\mathrm{CO}_{2}$ at the $\mathrm{P}$ and $\mathrm{T}$ of the calcite VI isentrope, calculated by extrapolation of the equation of state of Kerrick and Jacobs [1981]. The dotted line "CaO $+\mathrm{CO}_{2}$ " is the density of an equimolar mixture of $\mathrm{CaO}$ and $\mathrm{CO}_{2}$.

$$
\mathrm{E}_{\mathrm{p}}-\mathrm{E}_{\mathrm{o}}=\frac{1}{2}\left(\mathrm{P}_{\mathrm{H}}+\mathrm{P}_{\mathrm{o}}\right)\left(\mathrm{V}_{\mathrm{o}}-\mathrm{V}_{\mathrm{H}}\right)-\int_{\mathrm{V}_{\mathrm{H}}}^{\mathrm{V}_{\mathrm{o}}}(\mathrm{PdV})_{\text {release path }}
$$

Figure 11 shows, as an example, the measured release path from $24 \mathrm{GPa}$ (shot 598) and isentropes of calcite VI (Table 3) centered on the Hugoniot. The data lie very close to the calculated isentropes, indicating that to a reasonable degree of accuracy, the integral along the actual release path in equation (24) may be approximated by the integral along the calcite VI isentrope. Thus, for purposes of calculation and generalization, the postshock energy increase is given by

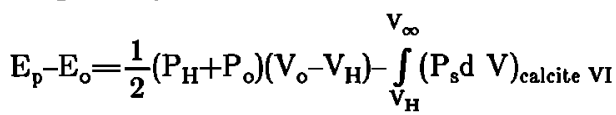

For the Dover chalk, anomalies in the Hugoniot or the release data are not observed; therefore we assume that transformation to calcite VI does not occur in the pressure range studied. Thus, in equation (25) the integration is carried out using the calcite I and II isentropes as limiting cases.

Figure 11 also shows the density of an equimolar mixture of $\mathrm{CaO}$ and $\mathrm{CO}_{2}$ at the temperatures and pressures of the calcite VI isentrope centered at the $24 \mathrm{GPa}$ data point. The density of $\mathrm{CaO}$ is approximated by the $\mathrm{CaO}$ (B1 phase) Hugoniot [Jeanloz and Ahrens, 1980]. The $\mathrm{CO}_{2}$ density was estimated for each $\mathrm{PT}$ point of the isentrope by extrapolation of the equation of state proposed by Kerrick and Jacobs [1981]. Use of the $\mathrm{CO}_{2}$ equation of state of Bottinga and Richet [1981] yields similar values. Extrapolation of these equations of state to the temperatures and pressures considered here is, of course, extremely speculative because the data on which they are based extend up to only $1273 \mathrm{~K}$ and $0.8 \mathrm{GPa}$. The calculated $\mathrm{CaO}+\mathrm{CO}_{2}$ curve indicates that if complete devolatilization occurred during the portion of the release measured, a much lower density release curve would be expected. However, within the error limits of the Hugoniot data and the release path, up to about $15 \%$ devolatilization at the lowest pressure point on the release path $(\sim 2.5 \mathrm{GPa})$ cannot be ruled out. For definitive determination of the exact point during (or immediately subsequent to) release at which devolatilization commences, more precise determinations of the release path must be made down to lower pressures.

Figure 12 shows the postshock energy gain versus pressure for the experimental data (using equation (24)) and for the model calculation (equation (25)). The agreement between the two indicates that the model used and the parameters employed (Table 3 ) provide a self-consistent representation of the energy changes involved in shock compression and release of calcite. We can now compare the postshock energy content of the calcite with the energy required for devolatilization $\mathrm{E}_{1 \mathrm{v}}$.

The energy required for incipient decarbonation (volatilization) $\mathrm{E}_{\mathrm{IV}}$ can be calculated using the data of Robie et al. [1978]. It is important to bear in mind that the equilibrium of the reaction

$$
\mathrm{CaCO}_{3 \text { (calcite) }} \rightleftarrows \mathrm{CaO}_{\text {(solid) }}+\mathrm{CO}_{2 \text { (gas) }}
$$

is strongly influenced by the ambient pressure of $\mathrm{CO}_{2}, \mathrm{P}_{\mathrm{CO}_{2}}$. Thus for pure solid calcite and pure solid $\mathrm{CaO}$, the Gibbs free energy of reaction (26) $\Delta \mathrm{G}_{\mathrm{rx}}$ is

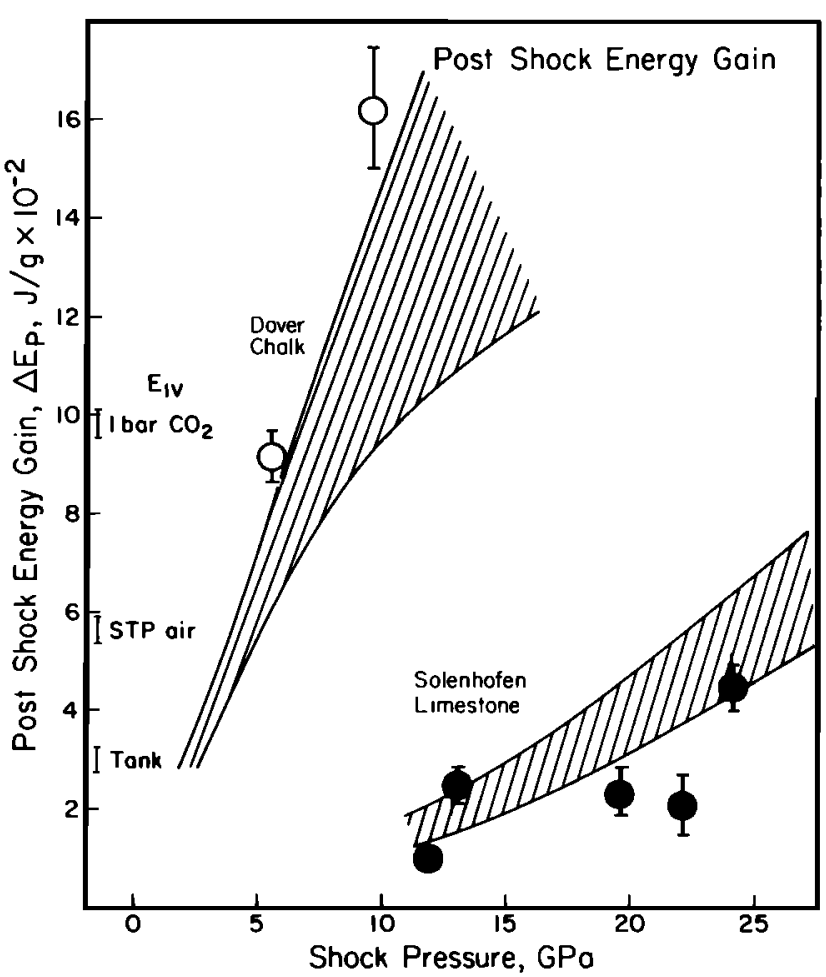

Fig. 12. Postshock energy increase $\Delta E_{p}$ as a function of shock pressure. Data points show $\Delta \mathrm{E}_{\mathrm{p}}$ calculated from the experimental release paths, using equation (24). Hatched regions represent values of $\Delta \mathrm{E}_{\mathrm{p}}$ calculated using calcite VI parameters (Table 3) for Solenhofen limestone and calcite I and II parameters for Dover chalk, using equation (25). The Hugoniot pressure of the porous material was calculated using equation (31). Also shown is energy of incipient vaporization $E_{\mathrm{IV}}$ calculated for several values of $\mathrm{P}_{\mathrm{CO}_{2}}$ "STP air" refers to $\mathrm{P}_{\mathrm{CO}_{2}}$ in dry air, $3.3 \times 10^{-4}$ bars; "Tank" refers to $\mathrm{P}_{\mathrm{CO}_{2}}$ in impact tank under shot conditions, about $4.3 \times 10^{-8}$ bars. 


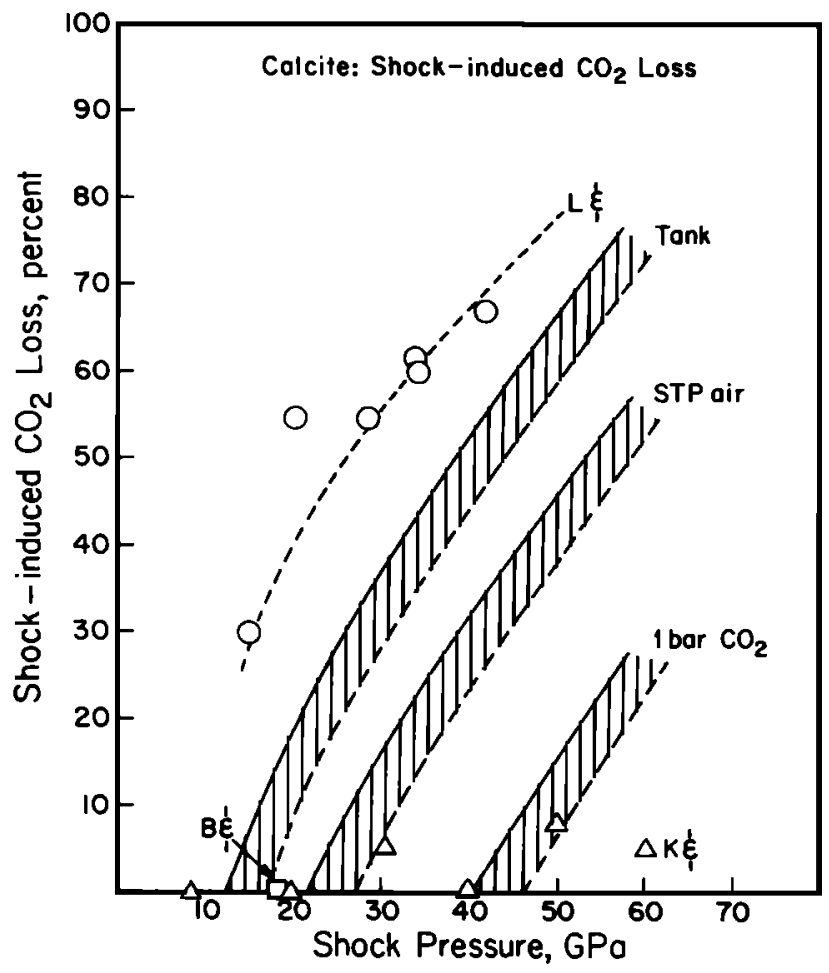

Fig. 13. Shock-induced $\mathrm{CO}_{2}$ loss as a function of peak shock pressure in experimentally shock loaded single crystal calcite. Circles, Lange and Ahrens [1983]; square, Boslough et al. [1982]; triangles, Kotra et al. [1983]. Also shown are $\mathrm{CO}_{2}$ losses calculated using shock entropy method for various values of ambient $\mathrm{CO}_{2}$ pressure. "Tank" refers to the ambient $\mathrm{CO}_{2}$ pressure in impact tank, about $4.3 \times 10^{-8}$ bars; "STP air" refers to the $\mathrm{P}_{\mathrm{CO}_{2}}$ in dry air at standard temperature and pressure conditions, about $3.3 \times 10^{-4}$ bars; Solid lines refer to the following combination of parameters of calcite $\mathrm{VI}_{j} \rho_{\mathrm{o}}=3.1 \mathrm{~g} / \mathrm{cm}^{3}, \mathrm{~K}_{\mathrm{os}}=95 \mathrm{GPa}, \mathrm{K}^{\prime}=3.5$, $\mathrm{E}_{\mathrm{trans}}=20 \mathrm{~J} / \mathrm{g}$. For dashed lines, $\rho_{\mathrm{o}}=3.0 \mathrm{~g} / \mathrm{cm}^{3}, \mathrm{~K}_{\mathrm{os}}=$ $75 \mathrm{GPa}, \mathrm{K}^{\prime}=4.1, \mathrm{E}_{\mathrm{trans}}=200 \mathrm{~J} / \mathrm{g}$.

$$
\Delta \mathrm{G}_{\mathrm{rx}}=\Delta \mathrm{G}_{\mathrm{rx}}^{\circ}+\mathrm{RT} \ln \mathrm{P}_{\mathrm{CO}_{2}}
$$

where the reference state for the solids is defined as pure solids at 1 bar pressure and the temperature of interest $T$, and for $\mathrm{CO}_{2}$ the reference state is pure $\mathrm{CO}_{2}$ gas at 1 bar $\left(10^{5} \mathrm{~Pa}\right.$ ) pressure and $\mathrm{T}$. Thus for $\mathrm{P}_{\mathrm{CO}_{2}}=1$ bar the temperature of incipient vaporization $T_{I V}$ is approximately $1171 \mathrm{~K}$ and the energy of incipient vaporization $E_{\mathrm{N}}$, given by

$$
\mathrm{E}_{\mathrm{IV}}=\int_{\mathrm{T}_{0}}^{\mathrm{T}_{\mathrm{IV}}} \mathrm{C}_{\mathrm{V} \text { (calcite) }} \mathrm{dT}
$$

is approximately $980 \mathrm{~J} / \mathrm{g}$ [Vizgirda and Ahrens, 1982; Kieffer and Simonds, 1980]. However, for $\mathrm{P}_{\mathrm{CO}_{2}} \sim \mathbf{3 . 3 \times 1 0 ^ { - 4 }}$ bar (corresponding to dry air at 1 bar total pressure ) $\mathrm{T}_{\mathrm{IV}}$ is approximately $800 \mathrm{~K}$, and $\mathrm{E}_{\mathrm{IV}}$ is about $530 \mathrm{~J} / \mathrm{g}$, and for $\mathrm{P}_{\mathrm{CO}_{2}} \sim 4.3 \times 10^{-8}$ bar (corresponding to dry air at a total presure of $100 \mu \mathrm{m} \mathrm{Hg}$ ), $T_{\mathrm{IV}}$ is about $596 \mathrm{~K}$ and $\mathrm{E}_{\mathrm{IV}}$ is $296 \mathrm{~J} / \mathrm{g}$. Thus $\mathrm{E}_{\mathrm{IV}}$ is strongly dependent on the explicit value of $\mathrm{P}_{\mathrm{CO}_{2}}$ used in the calculation of $\mathrm{T}_{\mathrm{IV}}$, and conversely, the amount of $\mathrm{CO}_{2}$ evolved during release may depend on the ambient $\mathrm{P}_{\mathrm{CO}_{2}}$

Previous applications of shock energy and entropy caculations to mineral devolatilization have implicitly (and arbitrarily) assumed that the partial pressure of the volatile species is equal to 1 bar [Ahrens and O'Keefe, 1972; Kieffer and Simonds, 1980; Vizgirda and Ahrens, 1982; Lange and Ahrens, 1982b]. Note that although $\mathrm{E}_{\mathrm{IV}}\left(\mathrm{P}_{\mathrm{CO}_{2}}\right), \mathrm{E}_{\mathrm{CV}}$ $\left(\mathrm{P}_{\mathrm{CO}_{2}}\right), \mathrm{S}_{\mathrm{IV}}\left(\mathrm{P}_{\mathrm{CO}_{2}}\right)$, and $\mathrm{S}_{\mathrm{CV}}\left(\mathrm{P}_{\mathrm{CO}_{2}}\right)$ are precisely known for calcite $\mathrm{I}$, in Figures 12 and 14 they are shown as ranges because of the ambiguity in whether it is actually calcite I, II, or III that decomposes upon release.

Such equilibrium considerations do not apply absolutely in a dynamic shock experiment, but evidence that ambient $\mathrm{CO}_{2}$ pressure affects the amount of evolved $\mathrm{CO}_{2}$ comes from consideration of the experimental details of the three studies of impact-induced volatilization of calcite cited earlier. Boslough et al. [1982] studied the evolution of $\mathrm{CO}_{2}$ during shock compression of calcite by capturing the evolved gas in an initially evacuated, confined chamber. For a shock pressure of $18 \mathrm{GPa}$, only $0.03-0.3 \%$ of the $\mathrm{CO}_{2}$ was volatilized, and the final $\mathrm{P}_{\mathrm{CO}_{2}}$ in the chamber at room temperature was between about $2.7 \times 10^{-3}$ to $7.2 \times 10^{-3}$ bars (M. Boslough, personal communication, 1984). For $\mathrm{P}_{\mathrm{CO}_{2}}=6 \times 10^{-3} \quad$ bars, $\quad \mathrm{T}_{\mathrm{IV}}=900 \mathrm{~K}$ and $\mathrm{E}_{\mathrm{IV}}=648 \mathrm{~J} / \mathrm{g}$. The studies of Lange and Ahrens [1983, and unpublished manuscript, 1985] were performed using vented assemblies [Lange and Ahrens, 1982b]; therefore the final $\mathrm{P}_{\mathrm{CO}_{2}}$ was that of air, $3.4 \times 10^{-4}$ bar. For $\mathrm{P}_{\mathrm{CO}_{2}}=3.4 \times 10^{-4}$ bar, $\mathrm{T}_{\mathrm{IV}}=800 \mathrm{~K}$, and $\mathrm{E}_{\mathrm{IV}}=528 \mathrm{~J} / \mathrm{g}$. They found significant decarbonation; as much as $30 \%$ at pressures as low as $10 \mathrm{GPa}$ (see Figure 13). The analytical method was different in each of the two sets of experiments; Boslough et al. determined the amount of $\mathrm{CO}_{2}$ evolved, whereas Lange and Ahrens determined the amount of $\mathrm{CO}_{2}$ remaining in the recovered solid material. Nonetheless, it appears that at least part of the difference in results may be attributed to differences in $\mathrm{P}_{\mathrm{CO}_{2}}$. The results of

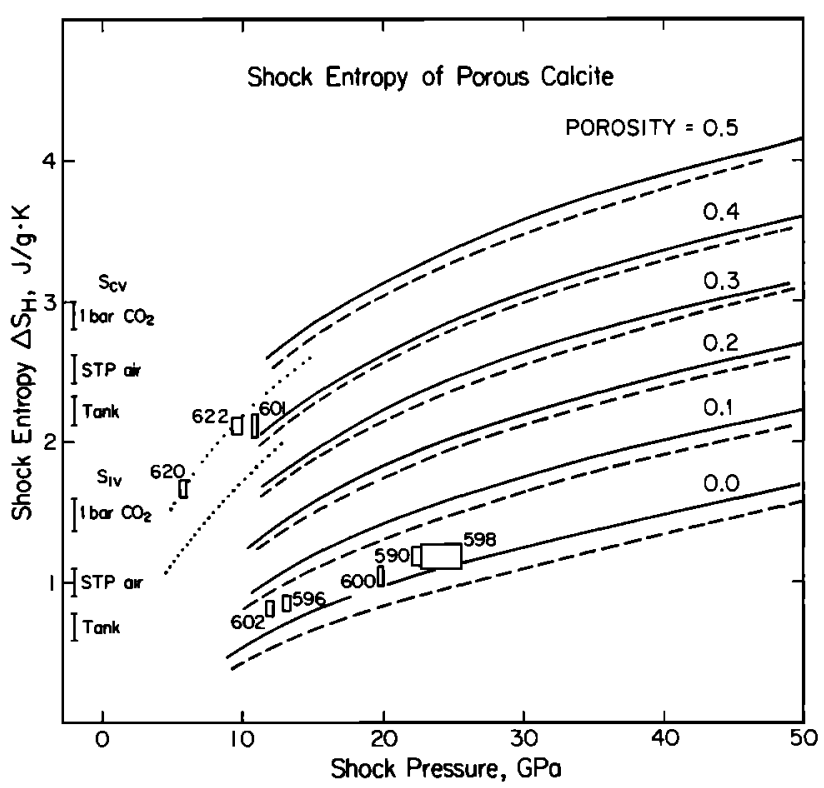

Fig. 14. Shock entropy as a function of shock pressure. The curves for porous calcite are calculated using the calcite Hugoniot of Adadurov et al. [1961] (Table 2), the correction for porosity embodied in equation (31), and the equation of state parameters for calcite VI listed in Table 3. $\mathrm{S}_{\mathrm{CV}}$ and $\mathrm{S}_{\mathrm{IV}}$ are calculated as a function of $\mathrm{P}_{\mathrm{CO}_{2}}$ as described in text. Solid and dashed curves assume transformation to calcite VI; dotted curves assume no transformation, i.e., the low-pressure Hugoniot of calcite is employed (Table 2). 
Kotra et al. [1983] differ from thóse discussed above because their targets (both vented and nonvented) were exposed to the $\mathrm{CO}_{2}$-rich muzzle gases from the gun barrel. The very low fraction of $\mathrm{CO}_{2}$ volatilized as a function of shock pressure obtained by these workers may be caused by very high $\mathrm{P}_{\mathrm{CO}_{2}}$ during release.

There are several implications of these results.

1. The release paths determined in this study may not be completely comparable to the volatilization results of either Boslough et al. or Lange and Ahrens, inasmuch as the experiments reported here were performed at about 100 $\mu \mathrm{m}$ air pressure $\left(\mathrm{P}_{\mathrm{CO}_{2}} \sim 4.3 \times 10^{-8}\right.$ bar $)$. It is likely, however, that any differences would occur at release pressures lower than the lowest pressure for which we were able to obtain data.

2. The evolution of $\mathrm{P}_{\mathrm{CO}_{2}}$ must be taken into account when calculating the evolution of impact-induced planetary atmospheric $\mathrm{CO}_{2}$ content. Note also that these considerations apply to the shock entropy criterion for vaporization upon release Ahrens and O'Keefe, 1972; Zel'dovich and Raizer, 1967] because this method also depends on the identification of a $T_{\mathrm{IV}}$ for calculation of $\mathrm{S}_{\mathrm{IV}}$ (entropy of incipient vaporization). Furthermore, the equilibrium considerations apply to any shock devolatilization process, especially shock dehydration [cf. Boslough et al., 1980; Lange and Ahrens, 1982a, b].

Having demonstrated the consistency of experimental and theoretical postshock energy calculations, we now employ the postshock entropy method for further calculations of shock devolatilization of calcite [Zel'dovich and Raizer, 1967; Ahrens and O'Keefe, 1972]. This method uses the same parameters as the postshock energy method (i.e., $K_{0}, K^{\prime}, \rho_{0}$, and $\gamma$ of the high-pressure polymorph, Table 3 ) and thus gives similar values for pressures of incipient devolatilization. It is, however, more convenient to use because it does not require or assume knowledge of the exact release path. Instead, the entropy gain in the shocked state $\Delta \mathrm{S}_{\mathrm{H}}$ is calculated according to

$$
\Delta \mathrm{S}_{\mathrm{H}}=\mathrm{S}_{\mathrm{tr}}+\mathrm{C}_{\mathrm{v}} \ln \left(\mathrm{T}_{\mathrm{H}} / \mathrm{T}_{\mathrm{s}}\right)
$$

where $S_{\mathrm{tr}}$ is the entropy of transition from calcite I to calcite $\mathrm{VI}$ at 1 bar and $298 \mathrm{~K}$ and $\mathrm{T}_{\mathrm{H}}$ and $\mathrm{T}_{\mathrm{s}}$ are calculated by continuum methods (equation (18) [Zel'dovich and Raizer, 1967)). The entropy of transition has been estimated to be between -0.116 and $-0.086 \mathrm{~J} / \mathrm{g}$ on the basis of entropy-molar volume systematics [Vizgirda and Ahrens, 1982] and we have adopted the value of $-0.101 \mathrm{~J} / \mathrm{g}$ for use here (Table 3). Note that Vizgirda and Ahrens [1982] apparently fail to include $S_{t r}$ in the shock entropy calculations for calcite and aragonite. The shock entropy is dependent on $\mathrm{T}_{\mathrm{H}}$, which in turn is greatly influenced by the initial porosity of the material. Assuming isentropic release from the shocked state [Kieffer and Delaney, 1979; Jeanloz and Ahrens, 1979], and isentropic phase change upon release [Cowperthwaite and Ahrens, 1967], the entropy of the completely released state will be equal to that of the shocked state, and this value is compared to the entropy of incipient vaporization $\mathrm{S}_{\mathrm{IV}}$, where

$$
\mathrm{S}_{\mathrm{IV}}=\int_{\mathrm{T}_{\mathrm{o}}}^{\mathrm{T}_{\mathrm{TV}}} \frac{\mathrm{C}_{\mathrm{p}}}{\mathrm{T}} \mathrm{dT}
$$

where $C_{p}$ is the atmospheric pressure heat capacity at constant pressure [Robie et al., 1978]. As discussed above, $T_{\text {IV }}$ will be dependent on the $\mathrm{P}_{\mathrm{CO}_{2}}$ chosen. The entropy of complete vaporization at $T_{\mathrm{IV}}, \mathrm{S}_{\mathrm{cv}}$, is computed from the values of entropy as a function of temperature of Robie et al. [1978]. Figure 13 compares the impact-induced volatile loss at several values of $\mathrm{P}_{\mathrm{CO}_{2}}$, calculated using the shock entropy method, with the existing experimental data. The data of Boslough et al. [1982] and Kotra et al. [1983] are consistent with having been obtained at elevated $\mathrm{CO}_{2}$ pressures. The results of Lange and Ahrens [1983] were obtained at STP. The agreement between the STP calculation and the data is improved over the calculation assuming $\mathrm{P}_{\mathrm{CO}_{2}}$ equal to 1 bar, and the general shapes of the curves are similar. This suggests that the process modeled in the calculations are important for impact-induced devolatilization. On the other hand, the substantial level of disagreement is, of course, a clear indication that some other process must also be considered (see below)

Figure 14 is a plot of shock entropy versus shock pressure for calcite of varying porosities calculated using the calcite Hugoniot of Adadurov et al. [1961] and the parameters for calcite VI listed in Table 3. The Hugoniots for the porous material are calculated according to

$$
\mathrm{P}_{\mathrm{P}}=\mathrm{P}_{\mathrm{D}}\left\{1-\frac{\gamma}{2}\left(\frac{\mathrm{V}_{\mathrm{o}, \mathrm{D}}}{\mathrm{V}_{\mathrm{H}}}-1\right)\right\} /\left\{1-\frac{\gamma}{2}\left(\frac{\mathrm{V}_{\mathrm{o}, \mathrm{P}}}{\mathrm{V}_{\mathrm{H}}}-1\right)\right\}
$$

where $P_{p}$ and $P_{D}$ are the pressures at volume $V_{H}$ of the porous material and the dense material, respectively, $\gamma$ is the Gruneisen parameter, and $V_{o, p}$ and $V_{o, D}$ are the zeropressure volumes of the porous and dense materials, respectively [Zel'dovich and Raizer, 1967; Ahrens and O'Keefe, 1972]. The experimentally determined shock entropies from this study are also plotted. The results for the Solenhofen limestone (initial porosity about .04) indicate that $\mathrm{S}_{\mathrm{IV}}$ for $\mathrm{P}_{\mathrm{CO}_{2}}=4.3 \times 10^{-8}$ bar (dry air atmosphere at $100 \mu \mathrm{m} \mathrm{Hg}$ total pressure, the conditions of the particle velocity experiment) is reached at about 12-17 GPa, and that at about $25 \mathrm{GPa}$ between $20-30 \%$ of the $\mathrm{CO}_{2}$ would be volatilized. The results from the Dover chalk shots (initial porosity of 0.49 ) indicate that greater than $90 \%$ of the material would be decarbonated at $10 \mathrm{GPa}$ shock pressure under the experimental conditions. For an air atmosphere $\left(\mathrm{P}_{\mathrm{CO}_{2}}=3.3 \times 10^{-4}\right.$ bar $)$ the figure indicates a minimum pressure for incipient devolatilization of nonporous calcite of 21 to $32 \mathrm{GPa}$, compared with the experimental value of less than $10 \mathrm{GPa}$ determined by Lange and Ahrens.

The shock energy or entropy criteria for incipient and complete vaporization when applied using the ambient vapor composition (as opposed, for example, to an arbitrary assumption of 1 bar pressure of the volatile species) yield the lowest values of $E_{\mathrm{IV}}$ or $\mathrm{S}_{\mathrm{IV}}$ and thus predict the greatest amount of devolatilization consistent with equilibrium thermodynamics. We assume that the atmospheric reservoir is large and that the addition of volatile species from the sample does not affect $\mathbf{P}_{\text {volatile. Thus equilibrium }}$ thermodynamic considerations fail to describe the experimental results for Solenhofen limestone even when the most generous assumptions concerning the final state of equilibrium are made.

We therefore conclude that a mechanism for the localization of thermal energy such as the shear instability model [Grady, 1977, 1980; Horie, 1980] is required to explain the experimental observations. In the case of single crystal calcite the existing determinations of color temperature under shock support this conclusion. Kondo and Ahrens [1983] report a temperature of $3700 \mathrm{~K}$ and an emissivity of 0.0025 for single crystal calcite shocked to $40 \mathrm{GPa}$ This temperature is several times the continuum shock temperature of 1300-1500 K [Vizgirda and Ahrens, 1982]. Textural examination of recovered calcite shocked to 40 GPa suggests the presence of partially molten material into which shock released $\mathrm{CO}_{2}$ has been injected [M. A. Lange and T. J. Ahrens, manuscript in preparation, 1985]. D. R. Schmitt (personal communication, 1984) has measured a color temperature of $2455 \mathrm{~K}$ for single-crystal calcite shocked to $22.5 \mathrm{GPa}$.

The relationships between measured shock tempera- 


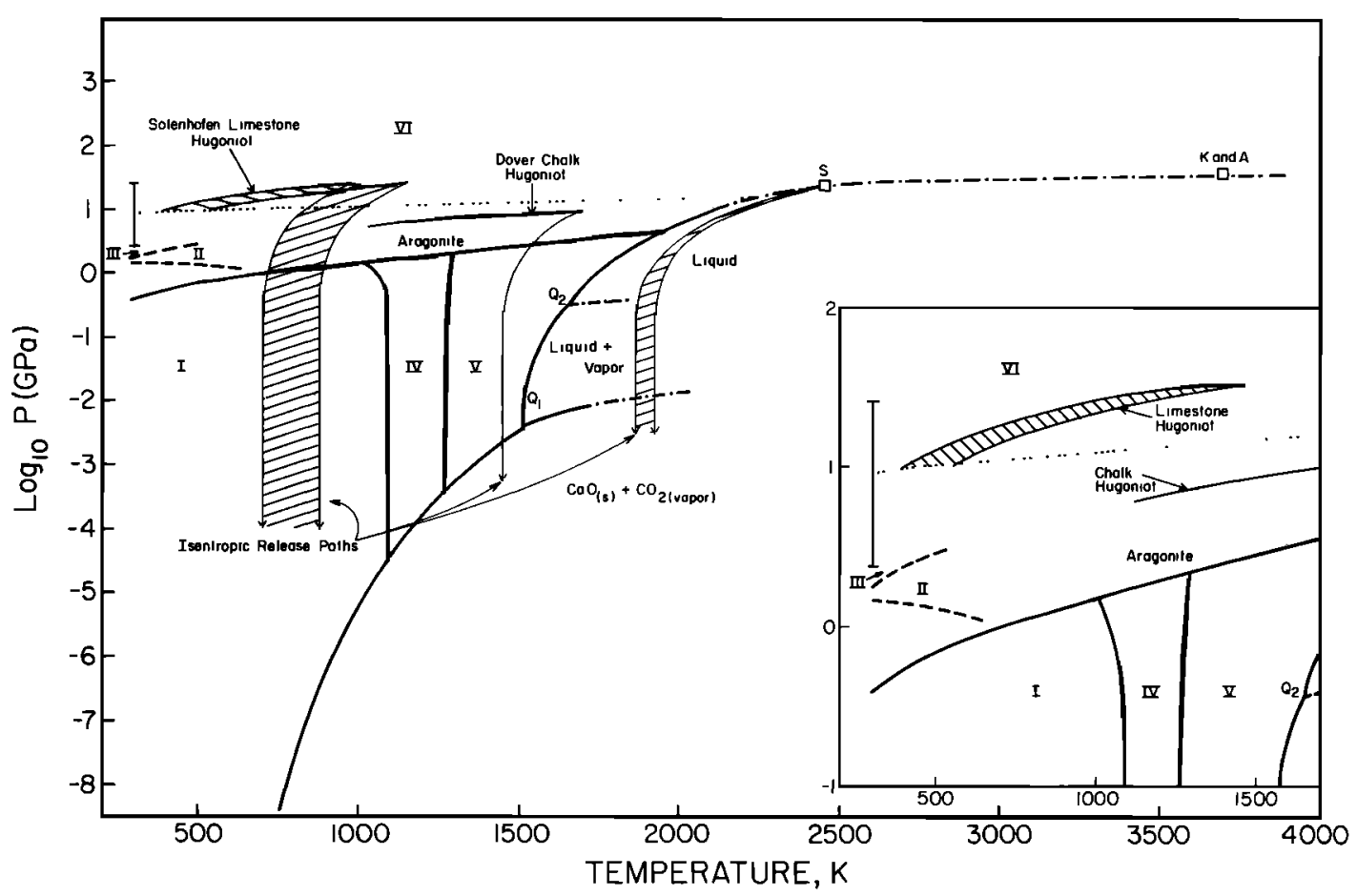

Fig. 15. $\mathrm{CaCO}_{3}$ phase diagram showing schematic paths of isentropic decompression from shocked states. The PT phase diagram is based on the results of Carlson [1983], Huang and Wyllie [1976], Irving and Wyllie [1973], Baker [1962], and Jamieson [1957]. Stability fields of each polymorph are labeled with the appropriate roman numeral. The range of Hugoniot and release path temperatures for Solenhofen limestone are calculated using the range of values of properties of calcite VI (Table 3). Hugoniot and representative release path temperatures of Dover chalk are based on the low-pressure calcite properties (Table 3). Open squares are shear band color temperature measurements on single-crystal calcite by Kondo and Ahrens [1983] (K $\&$ A) and by D. R. Schmitt (personal communication, 1984) (S). These are interpreted as representing points on the fusion curve. The representative isentropic release path for the point $\mathrm{S}$ is calculated using the calcite VI physical property data. Note that $10^{-4} \mathrm{GPa}$ corresponds to 1 bar pressure. $Q_{1}$ is the invariant point, at which $\mathrm{CaCO}_{3(\mathrm{~s})}, \mathrm{CaO}_{(\mathrm{s})}, \mathrm{CO}_{2(\text { vapor) }}$, and liquid coexist. $\mathrm{CaCO}_{3}$ melts incongruently between points $Q_{1}$ and $Q_{2}$ and melts congruently at pressures higher than $Q_{2}$. Metastable calcite II and III fields are separated by dashed lines. Extrapolated or inferred phase boundaries are shown by dash-dot lines. Dotted line represents the aragonite $\rightleftarrows$ calcite VI phase boundary constrained to lie below the limestone Hugoniot. Error bar on the dotted line represents the position of the line calculated using the range of property values for calcite VI listed in Table 3.

tures, calculated continuum temperatures, release paths, and the calcite devolatilization equilibria are shown in Figure 15. Figure 15 shows the $\mathrm{PT}$ phase diagram for $\mathrm{CaCO}_{3}$, the Hugoniot (continuum) P'T data for the Solenhofen limestone and Dover chalk reported here, and the measured shock temperatures of single-crystal calcite of $D$. R. Schmitt (personal communication, 1984) and Kondo and Ahrens [1983]. The calcite VI-liquid boundary is drawn through the two measured shock temperature values, but the conclusions drawn below do not depend critically on this particular placement of the boundary. Representative isentropic release paths, using the parameters in Table 3 , are shown for several points. The diagram illustrates that the isentropic release paths of shocked nonporous carbonates (Solenhofen limestone), calculated using continuum temperatures, do not cross into the $\mathrm{CaO}_{(\mathrm{s})}+\mathrm{CO}_{2}$ (vapor) field until very low pressures $\left(10^{-7}-10^{-8} \mathrm{GPa}\right)$ are reached. Shocked Dover chalk, particularly at shock pressures as high as $10 \mathrm{GPa}$, relaxes in to the solid plus vapor region at pressures of $10^{-3}$ to $10^{-4} \mathrm{GPa}$. However, isentropic release from points corresponding to measured shock temperatures pass in to the liquid field region at pressures of $10^{1} \mathrm{GPa}$ or higher, into the liquid plus vapor field at pressures of $10^{-1}$
GPa or higher, and then into the solid plus vapor region at pressures of about $10^{-2} \mathrm{GPa}$. The high measured shock temperatures are related to shear banding phenomena, and it thus appears that localization of thermal energy is an in tegral part of the devolatilization process. The diagram also indicates that the effect of $\mathrm{CO}_{2}$ pressure on the fraction devolatilized will be more modest in the case of shear band controlled devolatilization than in the case of devolatilization controlled by continuum temperatures.

\section{Conclusions}

Solenhofen limestone shocked into the calcite VI region retains its shear strength in the shocked state at pressures between about 12 and $20 \mathrm{GPa}$. Equilibrium thermodynamic calculation of the energy and entropy required for incipient devolatilization combined with calculated values of the postshock energy and entropy gain fail to predict quantitatively the amount of volatile loss upon release. This result indicates that inhomogeneous deformation processes occur in this pressure range. The shear bands may be sites of initiation of partial melting and nucleation of evolved $\mathrm{CO}_{2}$ upon release. Therefore the density of the 
shear bands created in this shock-pressure interval must be insufficient to modify the bulk mechanical properties of the polycrystalline aggregate. At shock pressures above about $20 \mathrm{GPa}$ loss of strength of the material may occur, implying that the shear band density is large enough to affect mechanical properties. These shear band related phenomena occur in a shock pressure range in which no solid-solid phase transitions are observed. Isentropic release paths of material initially at the shock pressure and the measured shock temperature pass through the vapor plus liquid field into the vapor plus solid field, giving further support to the concept that devolatilization is associated with shear band formation.

At shock pressures of about $10 \mathrm{GPa}$, Dover chalk $\left(\rho_{\mathrm{o}}=1.40 \mathrm{~g} / \mathrm{cm}^{3}\right)$ appears to have lost its shear strength, but at $5 \mathrm{GPa}$ the results are ambiguous. Postshock entropy calculations indicate that greater than $90 \%$ of the $\mathrm{CO}_{2}$ is devolatilized upon release from $10 \mathrm{GPa}$ pressure.

Equilibrium calculations and experimental observations indicate that the amount of devolatilization of volatilebearing minerals upon impact is dependent on the ambient partial pressure of the volatile species. The shock pressure required for incipient devolatilization increases with ambient volatile species partial pressure. This effect causes the range of planet sizes in which partial devolatilization of carbonates occurs to be larger than that calculated based on devolatilization experiments carried out in air [Lange and Ahrens, 1983, and unpublished manuscript, 1985]. Volatile release is enhanced relative to that calculated by Lange and Ahrens in the early stages of planetary accretion, when the atmosphere is sparse, and is inhibited in the later stages, when the atmosphere is relatively dense.

Acknowledgments. We thank E. Gelle, M. Long, W. Miller, and C. Manning for their help in performing these experiments. M. Boslough, S. Rigden, and B. Svendsen provided valuable insight and discussion. The comments of anonymous reviewers helped improve the manuscript. Research supported by NASA NGL-05-002-105. Contribution 4134, Division of Geological and Planetary Sciences, California Institute of Technology.

\section{References}

Adadurov, G. A. D., D. B. Balashov, and A. N. Dremin, A study of the volumetric compressibility of marble at high pressures, Bull. Acad. Sci. USSR Geophys. Ser. 1961(5), 463-466, 1961.

Ahrens, T. J., and V. G. Gregson, Jr., Shock compression of crustal rocks: Data for quartz, calcite, and plagioclase rocks, J. Geophys. Res., $\underline{69}, 4839-4874,1964$.

Ahrens, T. J., and J. D. O'Keefe, Shock melting and vaporization of lunar rocks and minerals, Moon, 4, 214-249, 1972.

Ahrens, T. J., and J. T. Rosenberg, Shock Metamorphism: Experiments on quartz and plagioclase, in Shock Metamorphism of Natural Materials, edited by B. M. French and N. M. Short, pp. 59-81, Mono, Baltimore, Md., 1968.

Ahrens, T. J., J. L. Lower, and P. L. Lagus, Equation of state of forsterite, J. Geophys. Res., 76, 518-528, 1971.

Anderson, O. L., E. Schreiber, and R. C. Liebermann, Some elastic constant data on minerals relevant to geophysics, Rev. Geophys., 6, 491-524, 1968.

Baker, E. H., The calcium oxide-carbon dioxide system in the pressure range 1-300 atmospheres, Chem. Soc. J. $\underline{1962}, 464-470,1962$.

Bless, S. J., and T. J. Ahrens, Measurement of release wave speed in shock compressed polycrystalline alumina and aluminum, J. Geophys. Res., 81, 1935-1942, 1976.

Boslough, M. B., Shock-wave properties and high-pressure equations of state of geophysically important materials, Ph.D. thesis, Calif. Inst. of Technol., Pasadena, 1983.
Boslough, M. B., and T. J. Ahrens, Shock wave properties of anorthosite and gabbro, J. Geophys. Res, 90, 7814 $7820,1985$.

Boslough, M. B., R. J. Weldon, and T. J. Ahrens, Impactinduced water loss from serpentine, nontronite, and kernite, Proc. Lunar Planet. Sci.Conf., 11th, 2145-2158, 1980.

Boslough, M. B., T. J. Ahrens, J. Vizgirda, R. H. Becker, and S. Epstein, Shock-induced devolatilization of calcite, Earth Planet. Sci. Lett. 61, 166-170, 1982.

Bottinga, Y., and P. Richet, High pressure and temperature equation of state and calculation of the thermodynamic properties of gaseous carbon dioxide, Am. J. Sci., 281, 615-660, 1981 .

Bridgman, P. W., The high pressure behavior of miscellaneous minerals, Am. J. Sci., 237, 7-18, 1939.

Burdick, L., and D. L. Anderson, Interpretation of velocity profiles of the mantle, J.Geophys. Res., $80,1070-1074$, 1975.

Carlson, W. D., The polymorphs of $\mathrm{CaCO}_{3}$ and the aragonite-calcite transformation, in Carbonates: Mineralogy and Chemistry, Rev. Mineral., vol. 11, edited by R. J. Reeder, pp. 191-225, Mineralogical Society of America, Washington, D. C., 1983.

Courant, R., and K. O. Friedrichs, Supersonic Elow and Shock Waves, Wiley-Interscience, New York, 1948.

Cowperthwaite, M., and T. J. Ahrens, Thermodynamics of the adiabatic expansion of a mixture of two phases, Am. J.Phys. 35, 951-955, 1967.

Cowperthwaite, M., and R. F. Williams, Determination of constitutive relationships with multiple gauges in nondivergent flow, J.Appl. Phys., 42, 456-462, 1971.

Grady, D. E., Processes occurring in shock wave compression of rocks and minerals, in High Pressure Research: Applications in Geophysics, edited by M. H. Manghnani and S. Akimoto, pp. 389438, Academic, Orlando, Fla., 1977.

Grady, D. E., Interrelation of flow or fracture and phase transition in the deformation of carbonate rock, J. Geophys. Res., 84, 7549-7554, 1979.

Grady, D. E., Shock deformation of brittle solids, J. Geophys. Res., 85, 913-924, 1980.

Grady, D. E., Compression wave studies in Oakhall Limestone, Rep. SAND83-0370, Sandia Natl. Lab., Albuquerque, N. M., 1983.

Grady, D. E., and R. L. Moody, Shock and release equation of state of calcite, Rep. SAND85-0947, Sandia Natl. Lab., Albuquerque, N. M., 1985.

Grady, D. E., W. I. Murri, and G. R. Fowles, Quartz to stishovite: Wave propagation in the mixed phase region, J. Geophys. Res., 79, 332-338, 1974.

Grady, D. E., W. I. Murri, and P. S. DeCarli, Hugoniot sound velocities and phase transformations in two silicates, J. Geophys. Res., 80, 4857-4861, 1975.

Grady, D. E., R. E. Hollenbach, K. W. Schuler, and J. F. Callender, Compression wave studies in Blair dolomite, Rep. SAND 76-0005, Sandia Natl. Lab., Albuquerque, N. M., 1976.

Grady, D. E., R. E. Hollenbach, and K. W. Schuler, Compression wave studies on calcite rock, J. Geophys. Res., 83, 2839-2849, 1978.

Grieve, R. A. F., and P. B. Robertson, The terrestrial cratering record, 1, Current status of observations, Icarus, 83, 212-229, 1979.

Horie, $Y$., Thermodynamics of dislocations and shock compression of solids, Phys. Rev. B Condens. Matter, 21, 5549-5557, 1980.

Huang, W.-L., and P. J. Wyllie, Melting relations in the systems $\mathrm{CaO}-\mathrm{CO}_{2}$ and $\mathrm{MgO}-\mathrm{CO}_{2}$ to 33 kilobars, Geochim. Cosmochim. Acta, 40, 129-132, 1976.

Hughes, D. S., and J. H. Cross, Elastic wave velocities in 
rocks at high pressures and temperatures, Geophysics, 16, 577-593, 1951.

Irving, A. J., and P. J. Wyllie, Melting relationships in $\mathrm{CaO}-\mathrm{CO}_{2}$ and $\mathrm{MgO}-\mathrm{CO}_{2}$ to 36 kilobars with comments on $\mathrm{CO}_{2}$ in the mantle, Earth Planet. Sci. Jette, 20, 220 $225,1973$.

Jamieson, f. C., Introductory studies of high-pressure polymorphism to 24,000 bars by $x$-ray diffraction with some commen ts on calcite II, J. Geol, 65, 334-343, 1957.

Jeanloz, R., and T. J. Ahrens, Release adiabat measurements on minerals: The effect of viscosity, J. Geophys.Res., 84, 7545-7548, 1979.

Jeanloz, R., and T. J. Ahrens, Equations of state of $\mathrm{FeO}$ and $\mathrm{CaO}$, Geophys.J.R. Astron. Soc, 62, 505-528, 1980.

Kalashnikov, N. G., M. N. Pavloyskiy, G. V. Simakov, and R. F: Trunin, Dynañic compressibility of calcite-group minerals, Izy. Acad Sci. USSR Phys Solid Earth, Engl. Transl: $1973(2), 80-84,1973$.

Kerrick, D. M., and G. K. Jacobs, 'A modified RedlichKwong equation for $\mathrm{H}_{2} \mathrm{O}, \mathrm{CO}_{2}$, and $\mathrm{H}_{2} \mathrm{O}-\mathrm{CO}_{2}$ mixtures at elevated pressures and temperatures, Am. J.Sci. 281, 735-767, 1981.

Kieffer, S. W., and J. W. Delaney, Isentropic decompression of fluids from crustal and mantle pressures, J. Geophys. Res, 84, 161i-1620, 1979.

Kieffer, S. W., and C. H. Simonds, The role of volatiles and lithology in the impact cratering process, Rev. Geophys., 18, 143-181, 1980.

Kondo, K., and T. J. Ahrens, Heterogeneous shock-induced thermal radiation in minerals, Bhys. Chem. Miner, $\mathbf{q}$, 173-181, 1983.

Kotra, R. K., T. H. See, E. K. Gibson, F. Horz, M. J: Cintala, and R. S. Schmidt, Carbon dioxide loss in experimentally shocked calcite and limestone, Lunar Planet. Sci., 14, 401-402, 1983.

Lange, M. A., and T. J. Ahrens, The evolution of an impact generated atmosphere, Icarus, 51, 96-120, 1982a.

Lange, M. A., and T. J. Ahrens, Impact indueed dehydration of serpentine and the evolution of planetary atmospheres, Proc. Iunar Planet. Sci. Conf. 13th, part 1, L. Geaphys.Res, 87, suppl., A451-A456, 1982b.

Lange, M. A., and T. J. Ahrens, Shock-induced $\mathrm{CO}_{2}$ production from carbonates and a proto $\mathrm{CO}_{2}$ atmosphere on the Earth, Lunar Planet.Sci. 14, 419$420,1983$.

Larson, D. B., and G. D. Anderson, Plane shock wave studies of porous geologic media, J.Geophys. Res, 84, 4592-4600, 1979.

Marsh, S. P. (Ed.), LASh Shock Huroniot Data, University of California Press, Berkeley, 1980

McQueen, R. G., S. P. Marsh, and J. N. Fritz, Hugoniot equation of state of twelve rocks, J.Geophys. Res. 72 , 4999-5036, 1967.
McQueen, R. G., S. P. Marsh; J. W. Taylor, J. N. Fritz, and $W$. J. Carter, The equation of state of solids from shock wave studies, in High-Velocity Impact Phenomena, edited by R. Kinslow, pp. 293-417, Academic, Orlaindo, Fla., 1970.

Murri, W. J., D. E. Grady, and K. D. Mahrer, Equátion of state of rocks, Einal Rep. PYU-1883, Stanford Reśs. Inst., Menlo Park, Calif., 1975.

Peselnick, L., Elastic constants of Solenhofen limestone and their dependence on density and saturation, J. Geophys.Res., 67, 4441-4448, 1962.

Peselnick, L., and W. H. Wilson, Wave velocities and hysteresis in Solenhofen limestone for pressures up to 12 kilobars, J. Geophys. Res, 73, 3271-3280, 1968.

Petersen, C. F., W. J. Murri, and M. Cowperthwaite, Hugoniot and release-adiabat measurements for selected geologic materials, J. Geophys. Res, 75, 2063-2072, 1970.

Robie, R. A., B. S. Hemingway, and J. R. Fisher, Thermodynamic properties of minerals and related substances at $298.15 \mathrm{~K}$ and 1 bar $\left(10^{5}\right.$ pascals $)$ pressure and at higher temperatures, U.S.Geol. Sury. Bull, 1452, 1978.

Sammis, C., D. L. Andersón, and T. Jordan, Application of isotropic finite strain theory to ultrasonic and seismological data, J. Geophys, Res, 75; 4478-4480, 1970.

Schuler, K. W., and D. E. Grady, Compression wave studies in Solenhofen Limestone, Rep. SAND76-0279, Sandia Natl. Lab., Albuquerque, N. M., 1977.

Singh, A. K., and G. C. Kennedy, Compression of calcite to 40 kbar, J. Geophys. Res., 79, 2615-2622, 1974.

van Thiel, M., J. Shaner, and E. Salinas, Rep. UCRL 50108, vol. 3, Lawrence Livermore Lab., Livermore, Calif., 1977.

Vizgirda, J., and T. J. Ahrens, Shock compression of aragonite and irriplications for the equation of state of carbonates, J. Geophys.Res, 87, 4747-4758, 1982.

Wang, C., and M. Meltzer, Propagation of sound waves in a rock undergoing phase transformations, J. Geophys. Res., 78, 1293-1298, 1973

Zel'dovich, Ya., B., and Yu. P. Raizer, Physics of Shock Waves and High-Temperature Hydrodynamic Phenomena, vol. II, Academic, Orlando, Fla., 1967.

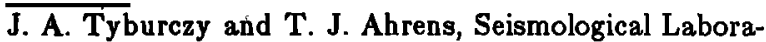
tory, California Institute of Technology, MA/252-21, 1201 E. California Blvd., Pasadena, CA 91125.

(Received November 26, 1984; revised August 5, 1985; accepted August 0, 1985.) 